\title{
COST-EFFECTIVENESS OF THE STREAM-GAGING PROGRAM IN IOWA
}

By I. L. Burmeister and O. G. Lara

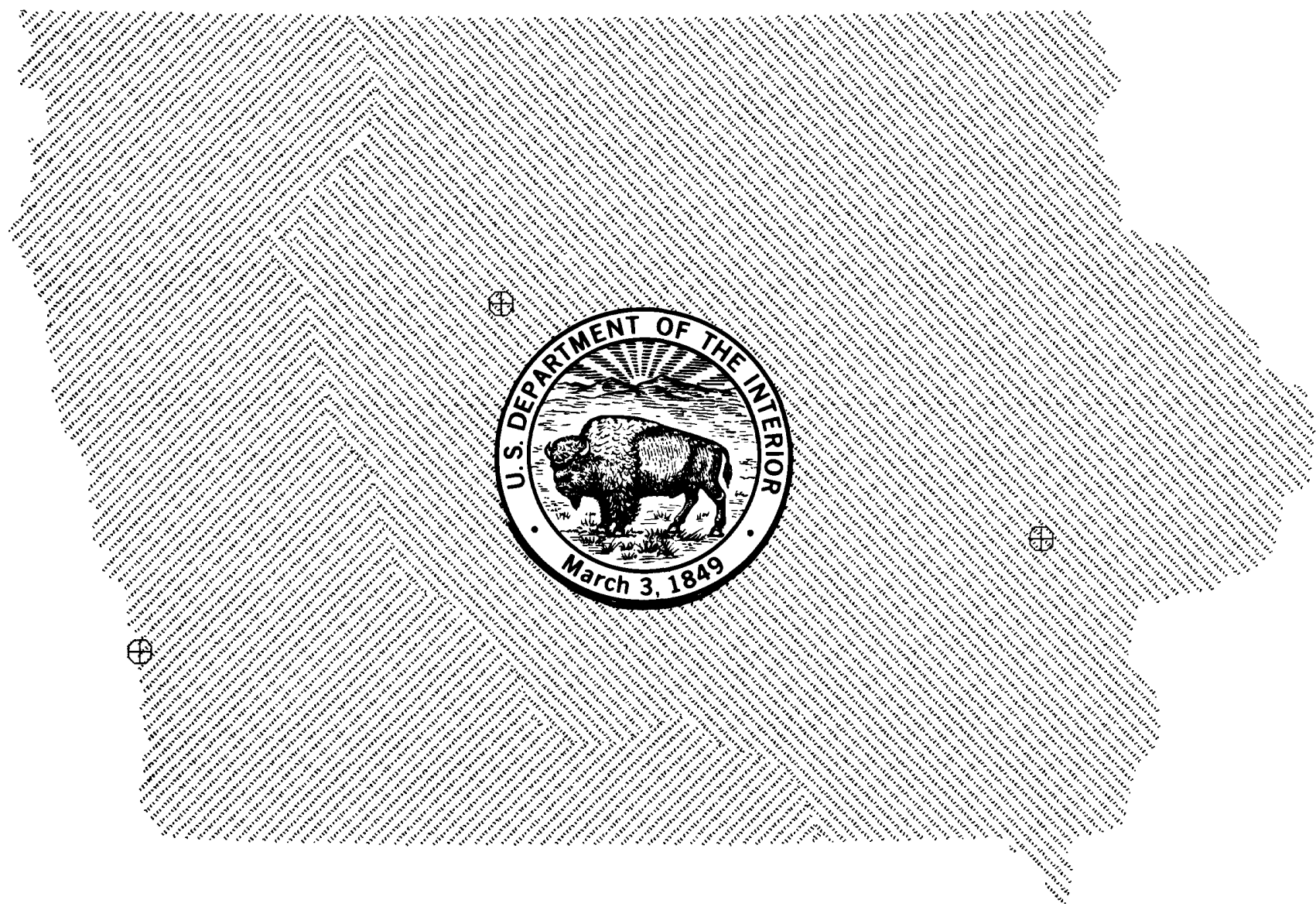

U. S. Geological Survey

Water-Resources Investigations Report 84-4171 


\section{UNITED STATES DEPARTMENT OF THE INTERIOR \\ WILLIAM P. CLARK, Secretary \\ GEOLOGICAL SURVEY \\ Dallas L. Peck, Director}

For additional information write to:

District Chief

U.S. Geological Survey Water Resources Division

P. O. Box 1230

lowa City, lowa 52244
Copies of this report can be purchased from:

Open-File Services Section Western Distribution Branch Box 25425, Federal Center Lakewood, Colorado 80225 (Telephone: (303) 236-7476) 


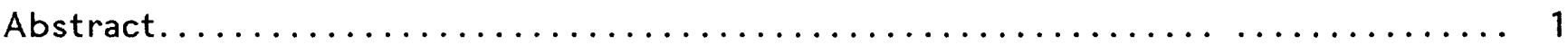

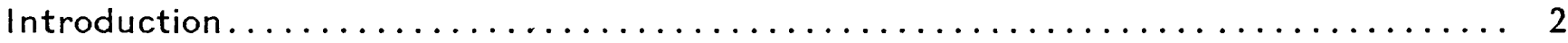

History of the stream-gaging program in lowa................. 4

Current stream-gaging program in lowa....................... 11

Uses, funding, and availability of continuous streamflow data............ 11

Data-use classes.................................. 11

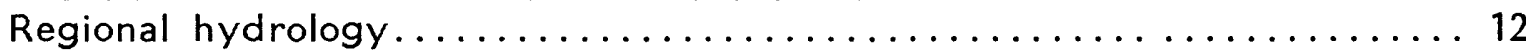

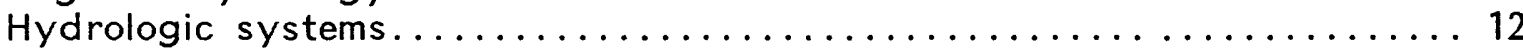

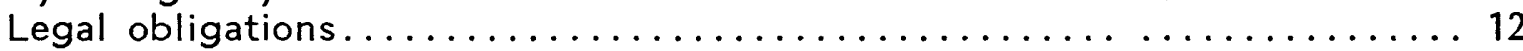

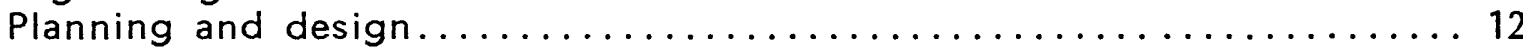

Project operation................................. 20

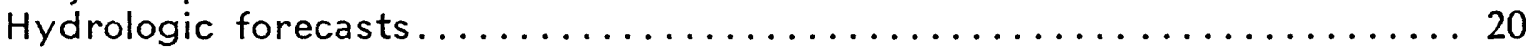

Water-quality monitoring............................. 20

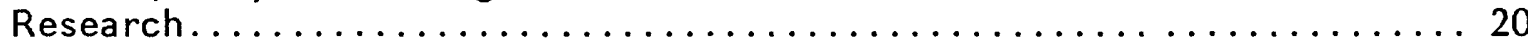

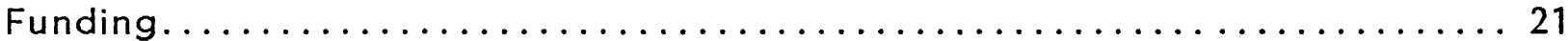

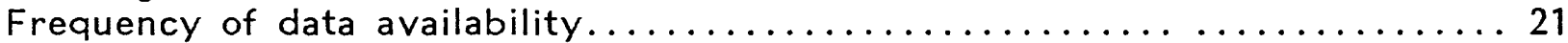

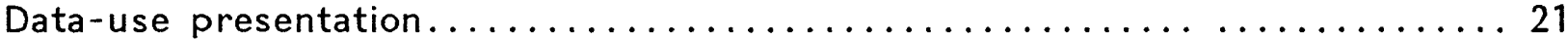

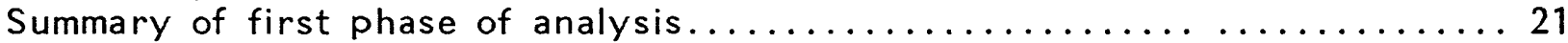

Alternative methods of developing streamflow information................23

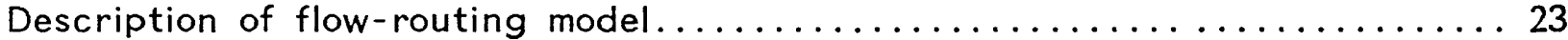

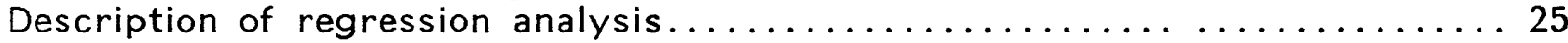

Selection of continuous streamflow stations for their

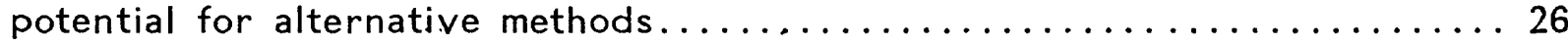

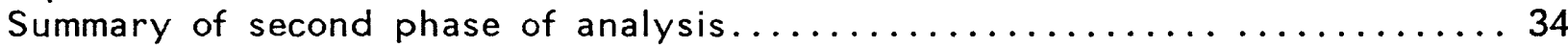

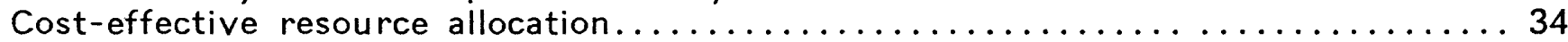

Introduction to Kalman-filtering for cost-effective

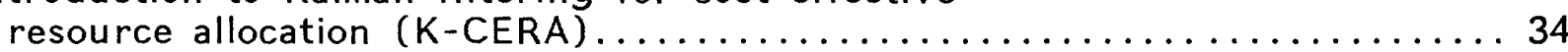

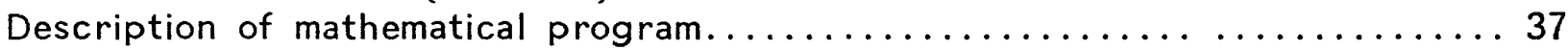

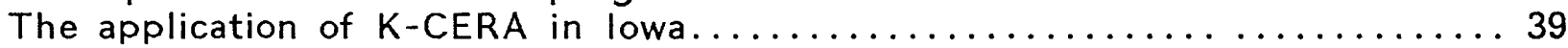

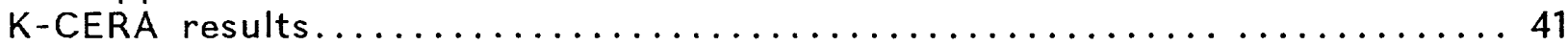

An application of K-CERA to stations on the Missouri River............48

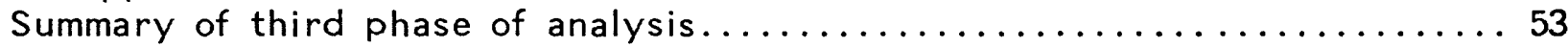

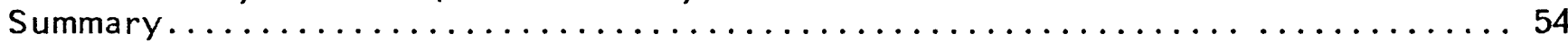

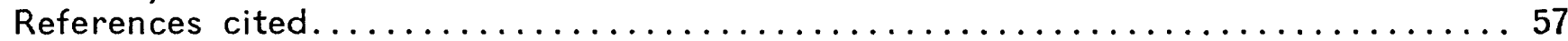

Supplemental data..................................... 59

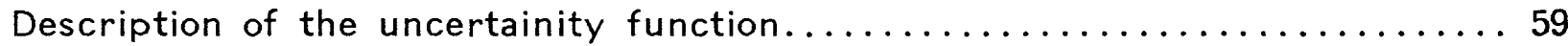

Relationship of visit frequency to lost record..................65 


\section{ILLUSTRATIONS}

Figure 1. Graph showing history of continuous stream

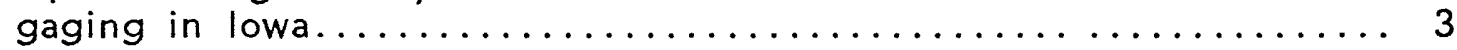

2. Map showing location of stream gages, District office, field headquarters and areas of responsibility ............... 5

3. Map showing study areas for alternative methods of providing streamflow information...................... 27

4. Sketch maps of study areas in the lowa and Cedar River basins................................ 28

5. Sketch maps of study areas in the Skunk and Des Moines River basins............................. 29

6. Sketch maps of study areas in the Floyd and Raccoon River basins........................... 30

7. Mathematical-programing form of the optimization of the routing of hydrographers $\ldots \ldots \ldots \ldots \ldots \ldots \ldots \ldots \ldots \ldots \ldots \ldots$

8. Tabular form of the optimization of the routing of hydrographers....................................... 36

9. Graph showing temporal average standard error per stream gage.............................. 42

10. Nomogram showing definition of downtime for a

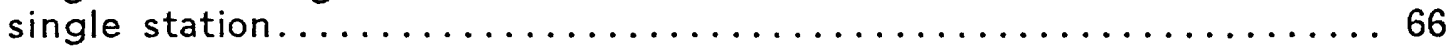

11. Diagram showing definition of joint downtime for

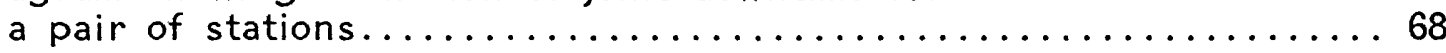

\section{TABLES}

Table 1. Selected hydrologic data for 122 surface-water

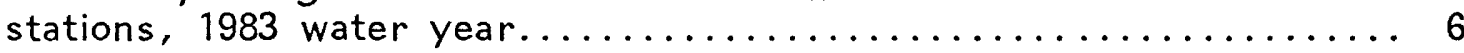

2. Uses, funding and availability of surface-water data from 122 stations, 1983 water year........................ 13

3. Selected reach characteristics used in the flowrouting studies................................... 31

4. Summary of flow-routing results and comparison between historic and simulated flows ...................... 31

5. Summary of regression modeling results and comparison

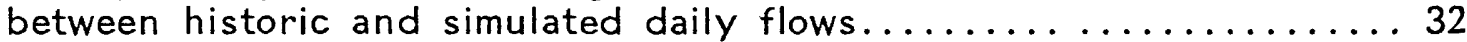

6. Summary of the Kalman-filtering analysis.................... 43

7. Summary of the routes that may be used to visit stations in lowa................................. 49

8. Selected results of K-CERA analysis...................... 50 
FACTORS FOR CONVERTING INCH-POUND TO METRIC (SI) UNITS

Multiply inch-pound units

$$
\text { foot }(\mathrm{ft})
$$

mile $(\mathrm{mi})$

square mile $\left(\mathrm{mi}^{2}\right)$

cubic foot $\left(\mathrm{ft}^{3}\right)$

cubic foot per second $\left(\mathrm{ft}^{3} / \mathrm{s}\right)$ by

Length

0.3048

1.609

Area

2.590

Volume

0.02832

\section{Flow}

0.02832
To obtain SI units

meter ( $m$ )

kilometer $(\mathrm{km})$

square kilometer $\left(\mathrm{km}^{2}\right)$

cubic meter $\left(\mathrm{m}^{3}\right)$

cubic meter per second $\left(\mathrm{m}^{3} / \mathrm{s}\right)$ 


\title{
COST-EFFECTIVENESS OF THE STREAMi-GAGING PROGRAM IN IOWA \\ By I. L. Burmeister, O. G. Lara
}

\begin{abstract}
This report documents the results of a study of the cost-effectiveness of the stream-gaging program in lowa. Data uses and funding sources were identified for the 122 surface-water stations (including reservoir, lake, stage only, and miscellaneous stations) operated by the U. S. Geological Survey in lowa. There are 110 continuous streamflow stations currently being operated in lowa with an annual budget of $\$ 592,000$.

The average standard error of estimation in continuous streamflow records is 11.4 percent. It was shown that this overall degree of accuracy at the 110 continuous streamflow stations could be improved to 10.5 percent if the gaging schedule was optimized.

A minimum budget of $\$ 543,000$ is required to operate the present streamgaging program in lowa. With this budget, routine visits to gages would be decreased to five during the open-water season and three during the winter. A budget less than this does not permit proper maintenance of the gages and recorders. At the minimum budget, the average standard error would be 12.5 percent. The maximum budget analyzed was $\$ 1,235,000$, which resulted in an average standard error of 4.2 percent. A 10 percent increase in the current budget to $\$ 656,000$ would result in a standard error of 8.4 percent.

There are still a few basins with drainage areas greater than 200 square miles that have no continuous streamflow data. Continuous streamflow gages need to be established in these basins as funds become available. All stations in the current program need to be maintained for the forseeable future.

Data simulated by using the flow-routing and regression methods for stations in 6 river basins do not meet the accuracy required for their data use. Other basins will be studied later to determine if alternative methods to meet accuracy standards are feasible.
\end{abstract}




\section{INTRODUCTION}

The U.S. Geological Survey is the principal Federal agency collecting surfacewater data in the Nation. The data are collected in cooperation with State and local governments and other Federal agencies. The Geological Survey presently (1983) is operating approximately 8,000 continuous-record gaging stations throughout the Nation. Some of these records extend back to the turn of the century. Any activity of long standing, such as the collection of surface-water data, needs to be reexamined at intervals, if not continuously, because of changes in objectives, technology, or external constraints. The last systematic nationwide evaluation of the streamflow-information program was completed in 1970 and is documented by Benson and Carter (1973). The Geological Survey presently (1983) is undertaking another nationwide analysis of the stream-gaging program that will be completed in 5 years with 20 percent of the program being analyzed each year. The objective of this analysis and report is to define and document the most cost-effective means of obtaining and providing streamflow information.

For every continuous-record gaging station, the first phase of the analysis identifies the principal uses of the data and relates these uses to funding sources. Gaged sites for which data are no longer needed are identified, as are deficient or unmet data demands. In addition, gaging stations are categorized as to whether the data are available to users in a real-time sense, on a provisional basis, or at the end of the water year.

The second phase of the analysis is to identify less costly alternate methods of obtaining and providing the needed information; among these are flow-routing models and statistical methods. The stream-gaging activity no longer is considered just a network of measuring points, but rather an integrated information system in which data are provided both by measurements and synthesis.

The final phase of the analysis involves the use of Kalman-filtering and mathematical-programing techniques to define strategies for operation of the necessary stations that minimize the uncertainty in the streamflow records for given operating budgets. Kalman-filtering techniques are used to compute uncertainty functions (relating the standard errors of computation or estimation of streamflow records to the frequencies of visits to the stream gages) for all stations in the analysis. A steepest descent optimization program uses these uncertainty functions, information on practical stream-gaging routes, the various costs associated with stream gaging, and the total operating budget to identify the visit frequency for each station that minimizes the overall uncertainty in the streamflow records. The stream-gaging program that results from this analysis will meet the expressed water-data needs in the most cost-effective manner.

This report is organized into five sections; the first being an introduction to the stream-gaging activities in lowa and to the study itself. The middle three sections each contain discussions of an individual phase of the analysis. Because of the sequential nature of the phases and the dependence of subsequent phases on the previous results, summaries are made at the end of each of the middle three sections. The study, including all phase summaries, is summarized in the final section. 


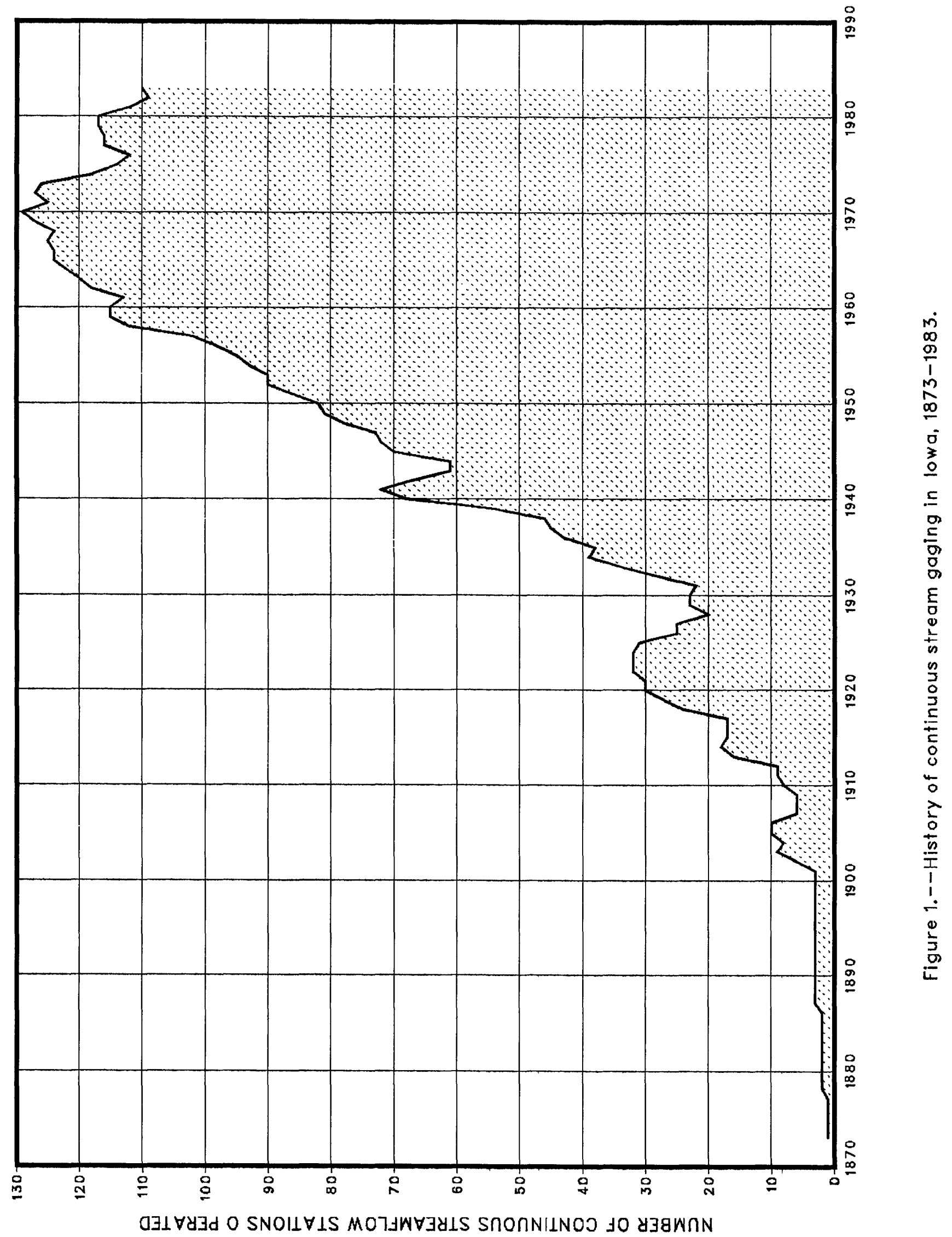


The program of surface-water investigations by the U. S. Geological Survey in lowa has increased rather steadily through the years as Federal and State interest in water resources has increased. The first Federal appropriations to the Geological Survey for collecting streamflow data in lowa were allocated in 1902. From 1902 until 1907, the stream-gaging network in lowa operated by the Geological Survey consisted of three stations that had been operated by the City of Boone prior to 1902 and seven additional stations established by the Survey. During this time the stream-gaging program in lowa was part of a larger program for the upper Mississippi River basin that was administered by the Chicago District (A. H. Horton, District Engineer). Congressional funding was discontinued in 1907 and not resumed until 1909. In 1909, Congress again appropriated funds for the newly formed Upper Mississippi River District, which included lowa, headquarted in Chicago, IL (W. G. Hoyt, District Engineer). Four stations were reestablished in lowa in 1911. The State-Federal cooperative program for surface-water activities in lowa began in 1914 and has continued to the present (1983) except for 1928-32 when the program was discontinued during the Great Depression. Operations of surface-water activities in lowa were transferred to lowa in October 1932 when a Geological Survey district office was established at the Hydraulics Laboratory, University of lowa, lowa City. Rudy C. Kasel was appointed District Engineer and served until 1914. Subsequent district engineers were Larry C. Crawford (1914-49), and Vernal R. Bennion (1949-64). The title of the district-office supervisor was changed to that of District Chief in 1965. S. W. Wiitala held that position during 1965-78, followed by D. K. Leifeste (1978-82), and J. M. Klein (1982-). Several lowa cities, power companies, navigation interests and the University of lowa and lowa State University contributed much to the data-collection program in those early years by establishing and reading gages and analyzing specific flood events. Current involvement is mostly by financial support.

The oldest streamflow records in lowa are the annual peak stages for the Mississippi River at Davenport which are complete since 1860. Daily streamflow records are complete for the Mississippi River at Clinton since 1873 and for the Mississippi River at Keokuk since 1878. These records were collected by the $U$. S. Engineers since 1860 and/or the Mississippi River Power Company since 1913. Other long-term stations are the Cedar River at Cedar Rapids (1902), lowa River at lowa City (1903), and Des Moines River at Keosauqua (1903). The historical number of continuous streamflow stations operated within lowa is given in figure 1.

The crest-stage, partial-record program was started in 1952 with 55 stations. This program was in response to the need to define flood-frequency relations and the general hydrology of small drainage areas. This network was expanded to 127 stations in 1966. Annual peak discharges from these stations were compiled with those of the continuous streamflow stations for the analysis of flood frequency in lowa (Lara, 1973).

The streamflow-data program in lowa was evaluated on the basis of past records, present goals and needs in 1970. Streamflow characteristics of monthly and annual mean discharge, standard deviation of mean discharge, flood-volume, peak and low-flow discharge were compiled for all stations with 10 or more years of unregulated streamflow record. Numerous basin characteristics were defined including drainage area, channel slope and length, mean basin elevation, annual precipitation and snowfall, rainfall intensity, and soil index (Burmeister, 1970). 


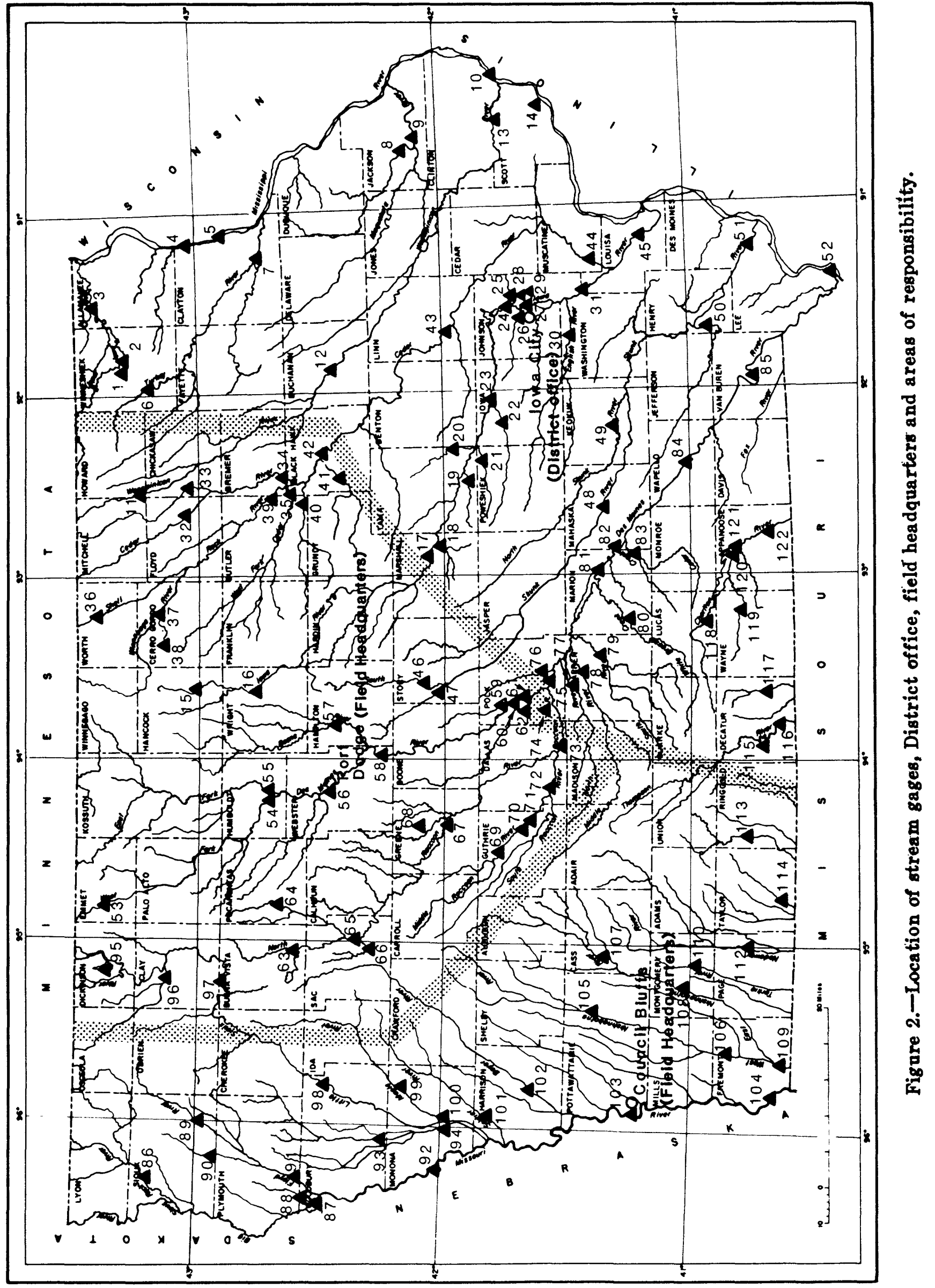




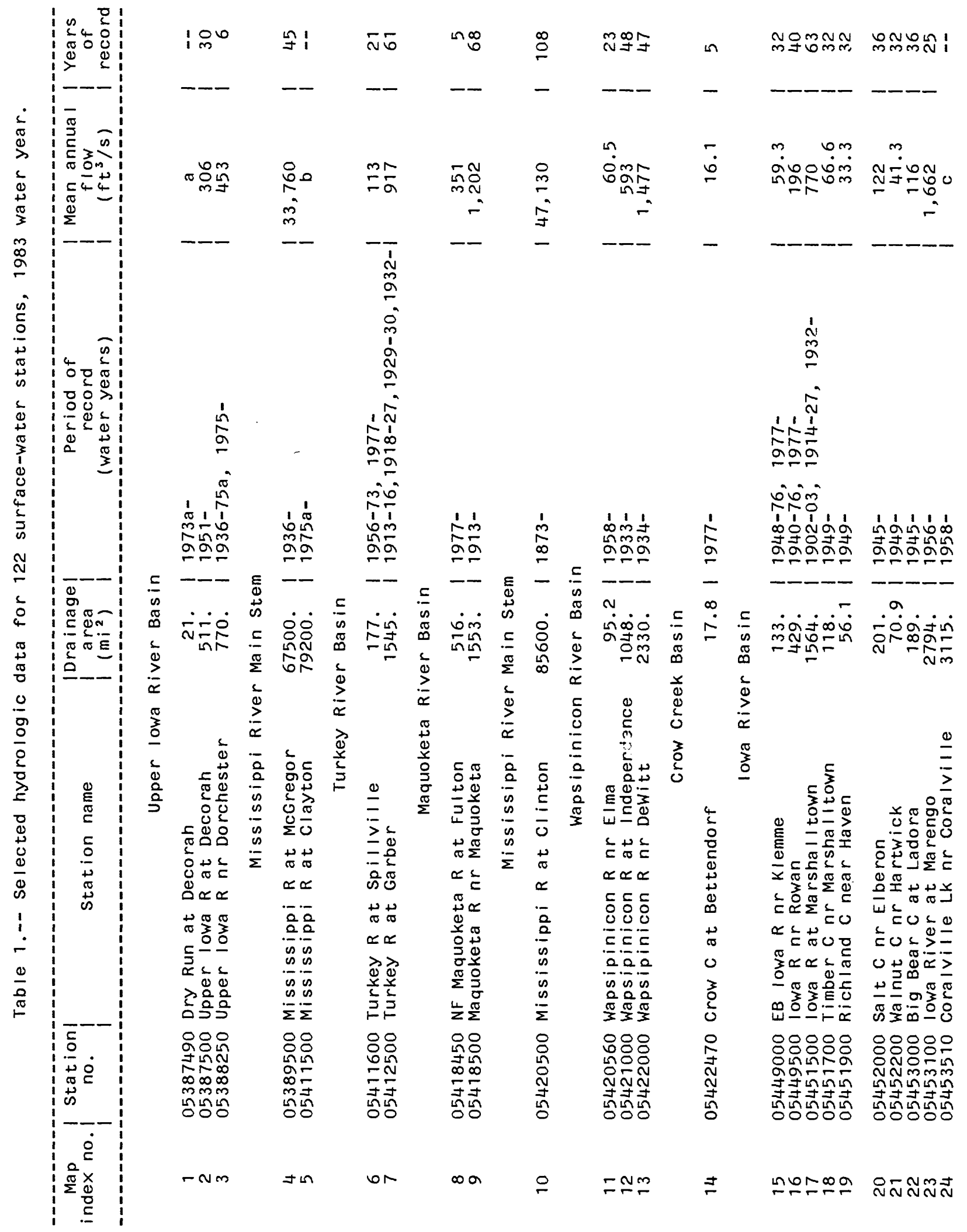









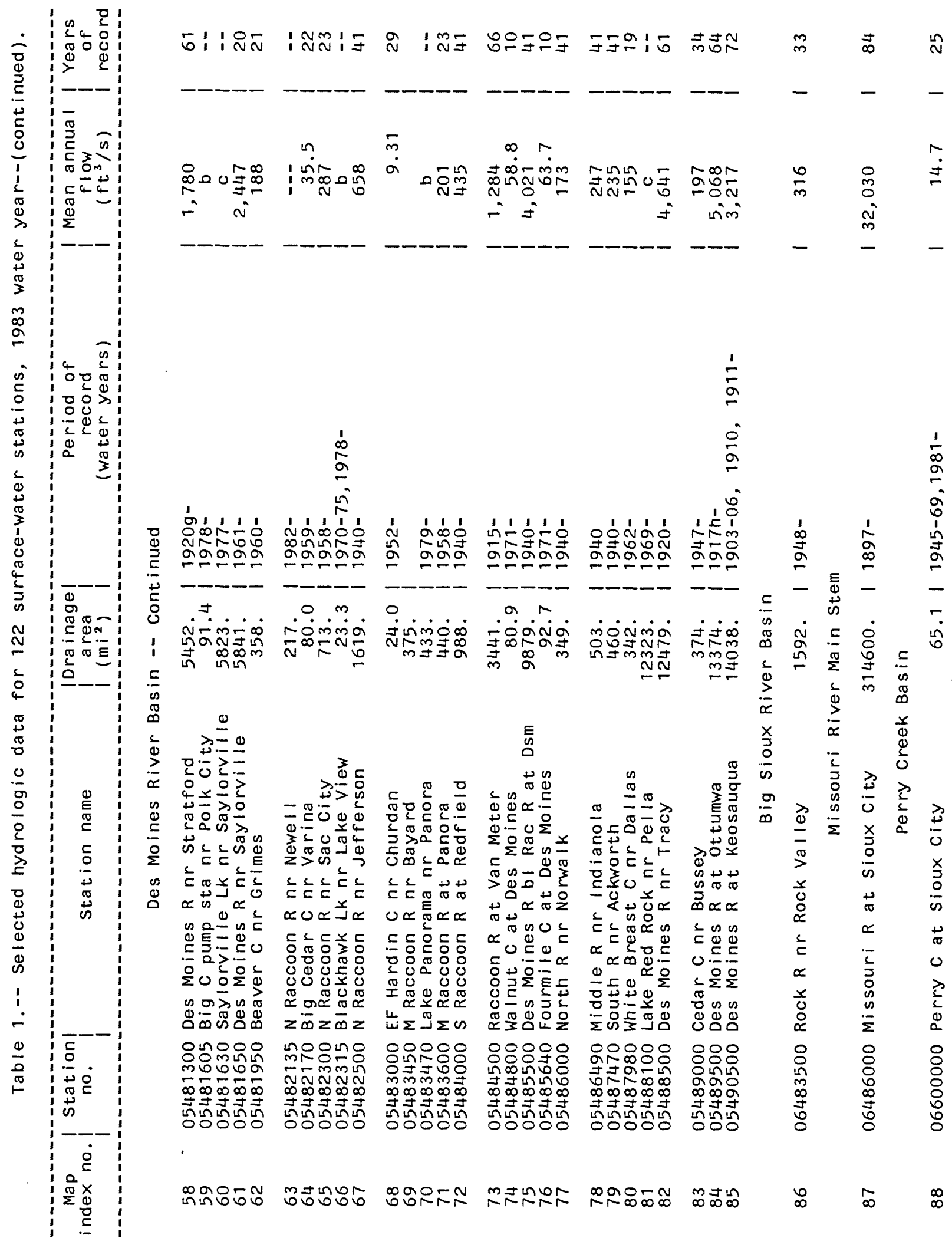




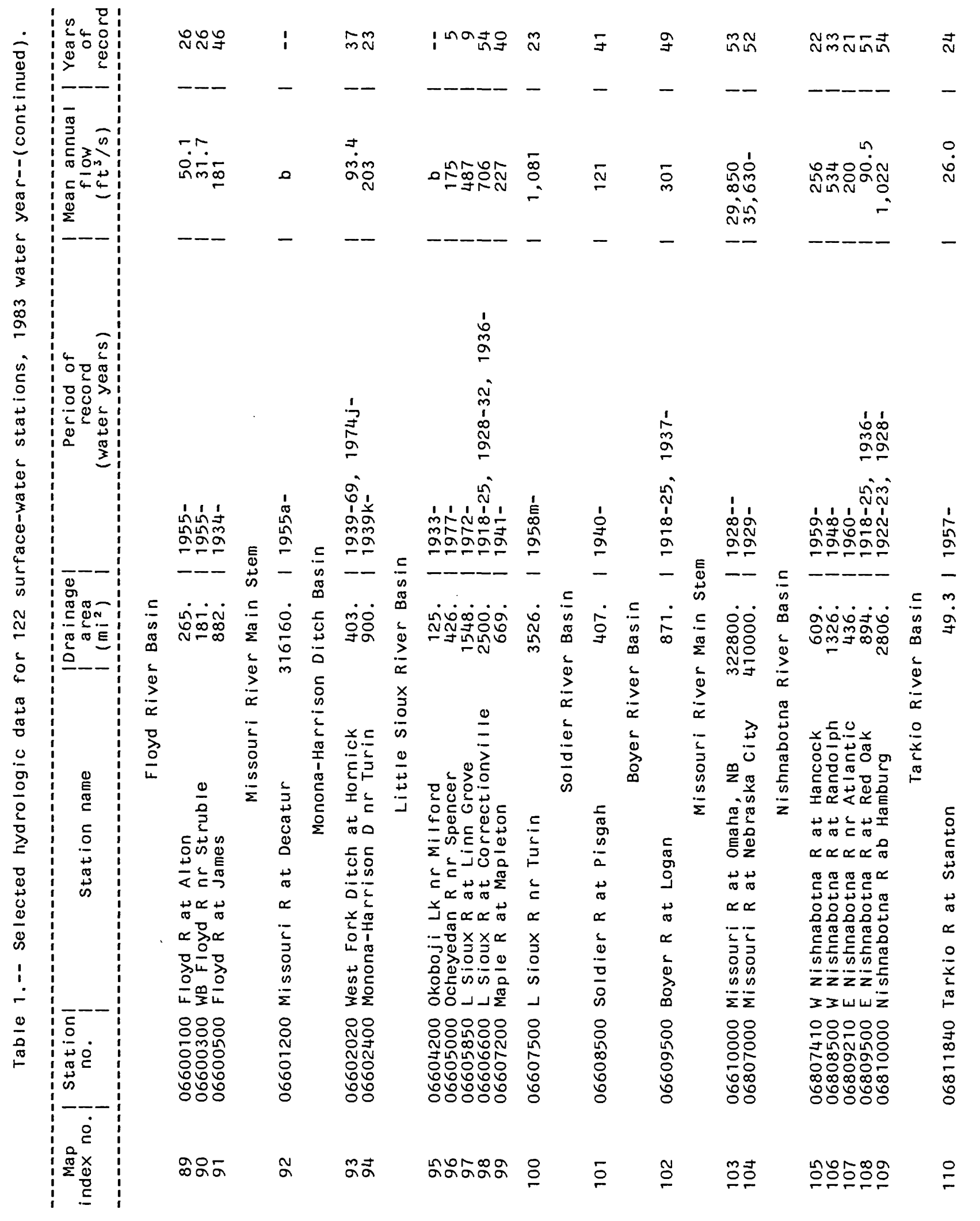




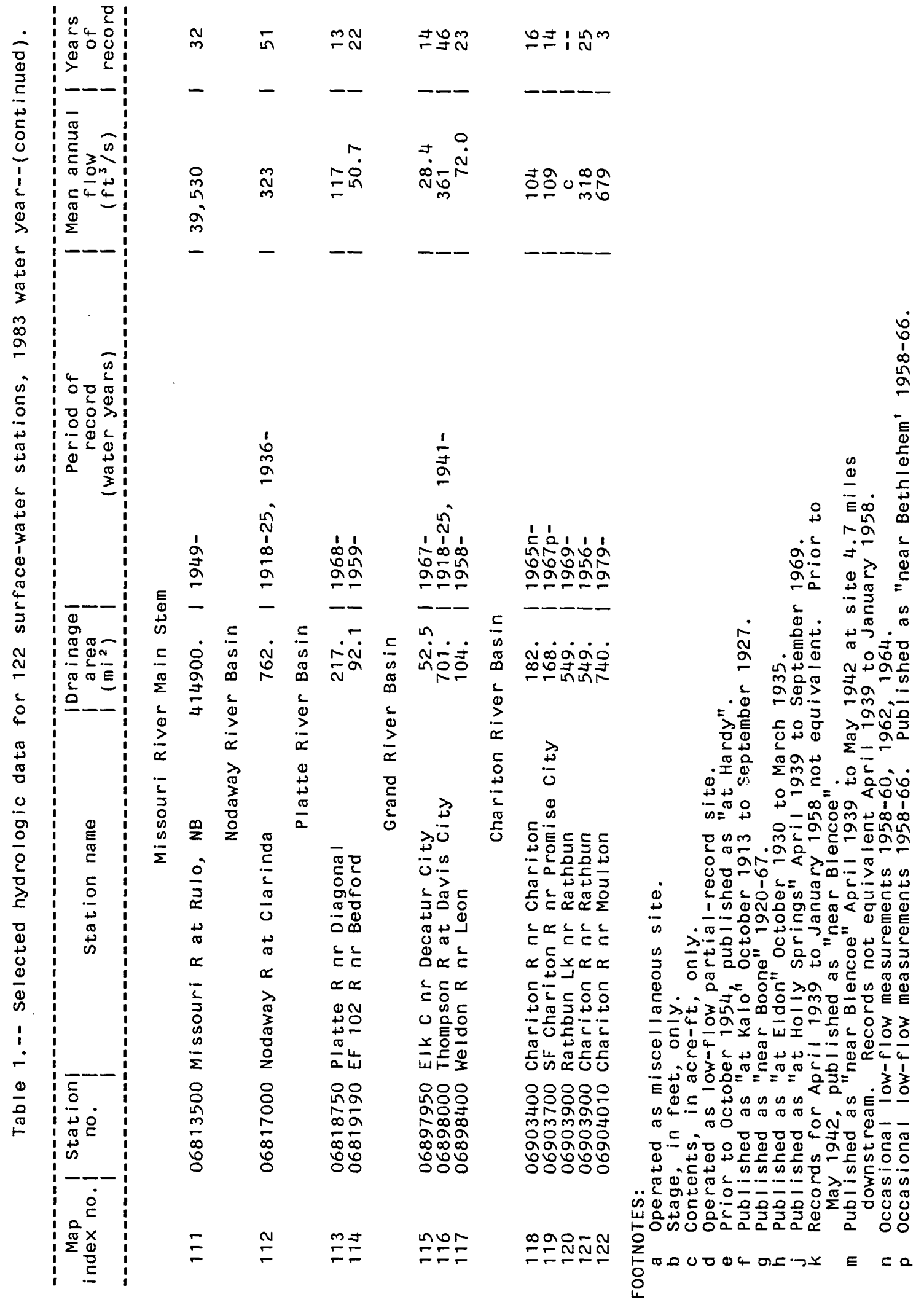


During 1983, 110 continuous streamflow stations, 126 crest-stage gages, and 4 stage-only or miscellaneous stations were operated by the $U$. S. Geological Survey in lowa. Of these stations, only the 110 continuous streamflow stations (fig. 2, table 1) were included in all three phases of the analysis. The cost of operating the 110 continuous streamflow stations during 1983 was $\$ 592,000$.

The 126 crest-stage gages, the 4 stage-only or miscellaneous stations, 4 lakestage stations, 11 continuous daily water-quality stations, and 43 ground-water observation wells were included only in the third phase of the analysis because the activities associated with operating, measuring, and maintaining these stations and wells are included in the hydrographers' work schedules when they visit the 110 continuous streamflow stations.

In addition to data for the 110 continuous streamflow stations in table 1, data for the 4 stage-only and miscellaneous stations, the 4 lake-stage stations, and the 4 reservoir-content stations also are included in table 1 because they are included routinely in the hydrographers' work schedules. The location of the additional 12 stations also is shown in figure 2.

The responsibility for data collection and records computation for the 110 continuous streamflow stations and the other 12 stations is shared by the District office at lowa City and the Field-Headquarters offices at Fort Dodge and Council Bluffs. The strategic location of each office decreases time and travel to the stations for which the offices are responsible, and consequently increases the opportunity to measure peak discharges during floods and to define the stagedischarge relationship at each station. The location of these offices and the assigned area of responsibility are shown in figure 2. Table 1 also provides the official U. S. Geological Survey eight-digit downstream-order station number, and name of each station.

\section{USES, FUNDING, AND AVAILABILITY OF CONTINUOUS STREAMFLOW DATA}

The relevance of a stream gage is defined by the uses that are made of the data that are produced from the gage. The uses of the data from each gage in the lowa program were identified by a survey of known data users. The survey documented the importance of each gage and identified gaging stations that may be considered for discontinuation.

Data uses identified by the survey were categorized into nine classes, defined below. The sources of funding for each gage and the frequency at which data are provided to the users also were compiled (table 2).

\section{Data-Use Classes}

The following definitions were used to categorize each known use of streamflow data for each continuous stream gage: 
For data to be useful in defining regional hydrology, a gaged stream needs to be largely unaffected by manmade storage or diversion. In this class of uses, the effects of man on streamflow are not necessarily small, but the effects are limited to those caused primarily by land-use and climate changes. Large volumes of manmade storage may exist in the basin providing the outflow is uncontrolled. These stations are useful in developing regionally transferable information about the relationship between basin characteristics and streamflow.

Sixty-four stations in the lowa network are classified in the regional hydrology data-use category. Four of the stations are special cases in that they are designated bench-mark or index stations. There is one hydrologic benchmark station in lowa, Elk Creek near Decatur City (06897950), which is used to indicate hydrologic conditions in watersheds relatively free of manmade alteration. Three index stations are used to indicate current hydrologic conditions for a national monthly summary. They are the Cedar River at Cedar Rapids (05464500), Des Moines River at Fort Dodge (05480500), and Nishnabotna River above Hamburg (06810000). Twelve stations are not funded for other uses. When sufficient hydrologic data are available to define the hydrologic characteristics of the basin, each of these stations will be considered for discontinuance. None are candidates at this time.

\section{Hydrologic Systems}

Stations that can be used for accounting, that is, to define current hydrologic conditions and the sources, sinks, and fluxes of water through hydrologic systems including regulated systems, are designated as hydrologic-systems stations. They include diversions and return flows and stations that are useful for defining the interaction of water systems.

Forty-four streamflow stations in the lowa network are classified in the hydrologic-systems category including the 4 bench-mark and index stations. They are used to account for the current and long-term conditions of the hydrologic systems that they gage.

\section{Legal Obligations}

Some stations provide records of flows for the verification or enforcement of existing treaties, compacts, and decrees. The legal-obligation category contains only those stations that the U. S. Geological Survey is required to operate to fulfill a legal responsibility. There are no stations in the lowa program that exist to fulfill a legal responsibility of the Geological Survey.

\section{Planning and Design}

Gaging stations in this category of data use are used for the planning and design of a specific project or group of structures. For example, streamflow data are needed for the design of dams, reservoir storage, flood control, levees, floodwalls, navigation systems, water supplies, hydropower plants, or wastetreatment facilities. The planning- and design-category is limited to those stations that were instituted for such purposes and where this purpose is still valid. Currently, no stations in the lowa program are being operated for planning- or design-purposes but data from several stations were used in the past for the design of large reservoirs and flood walls. 


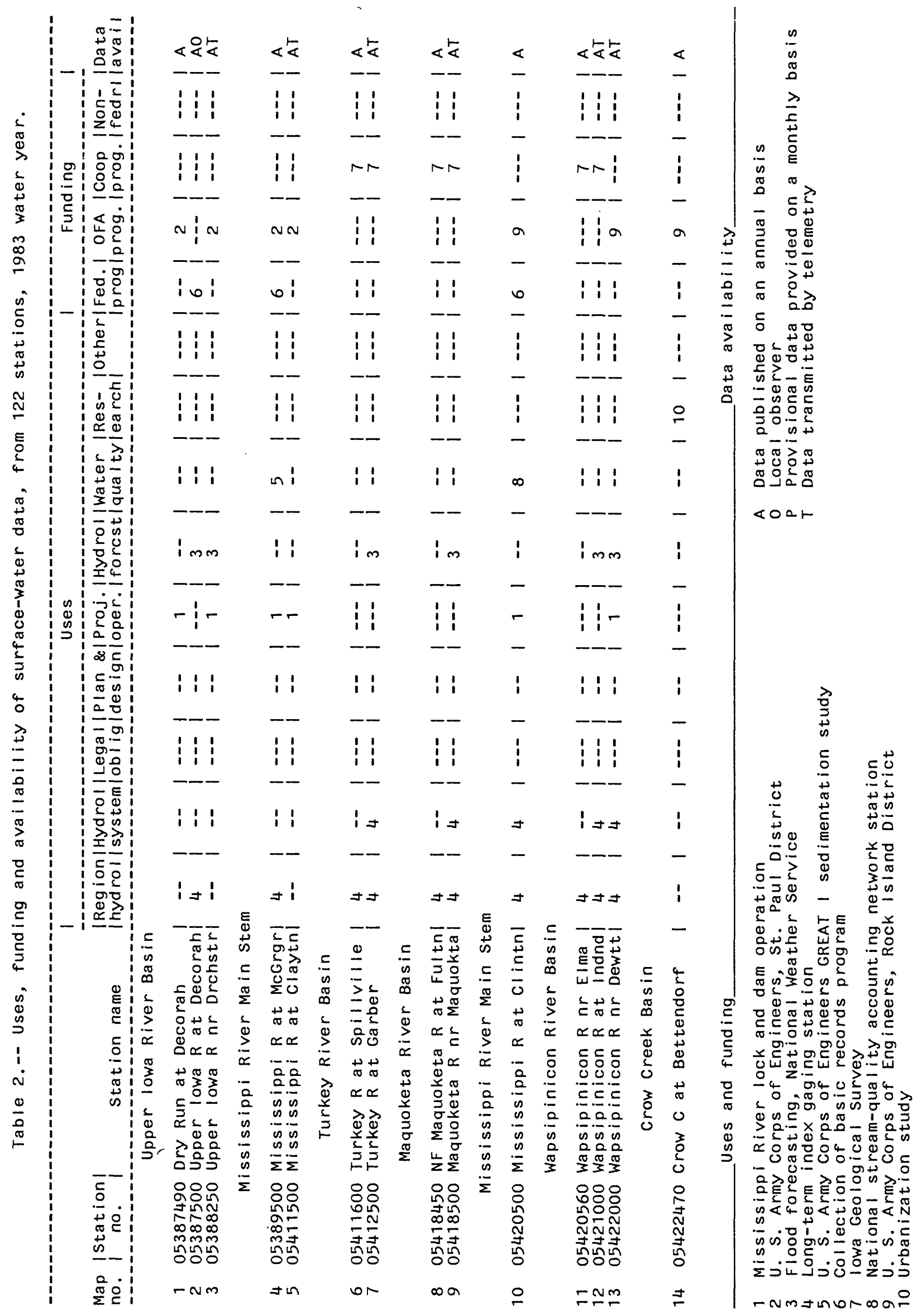




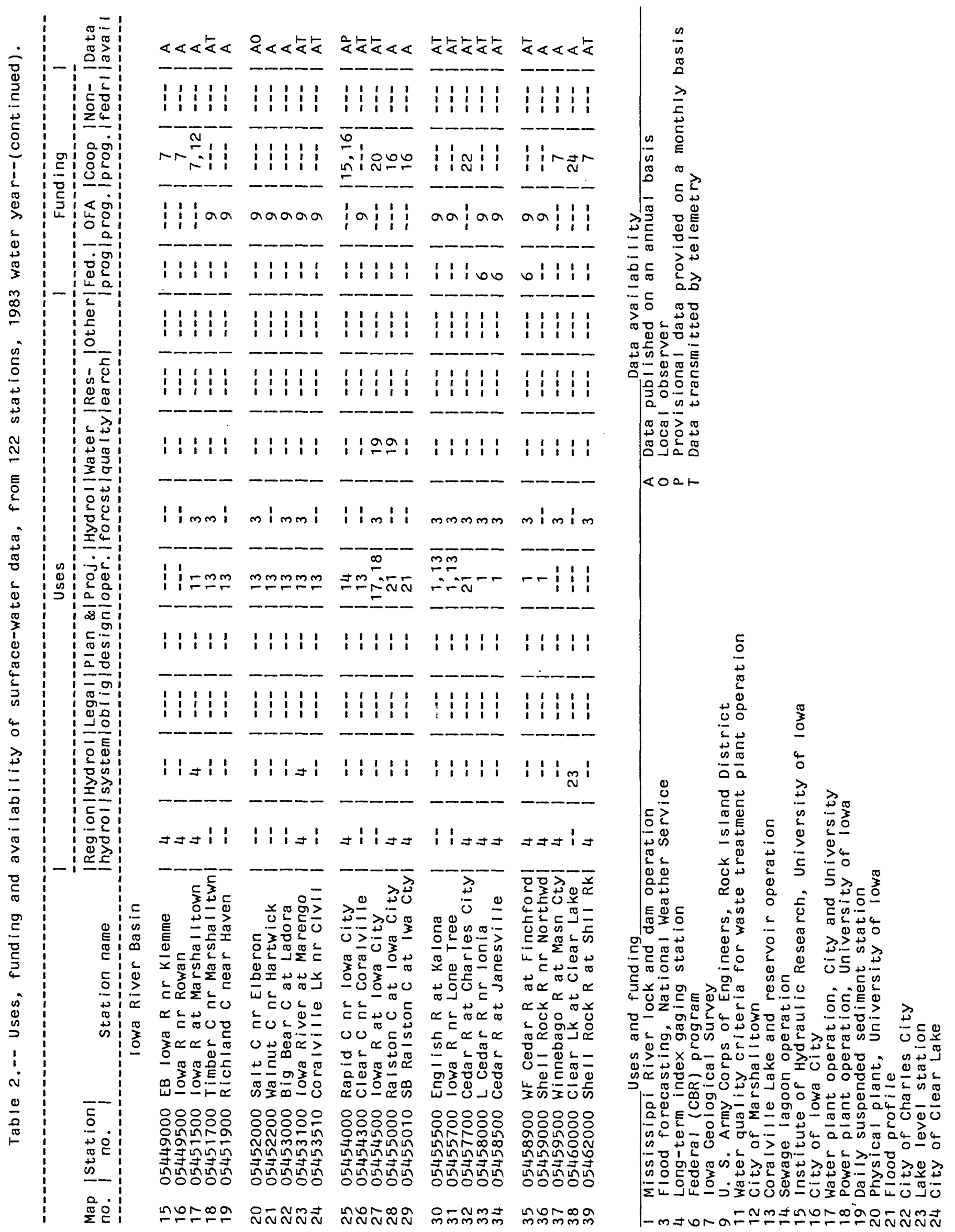




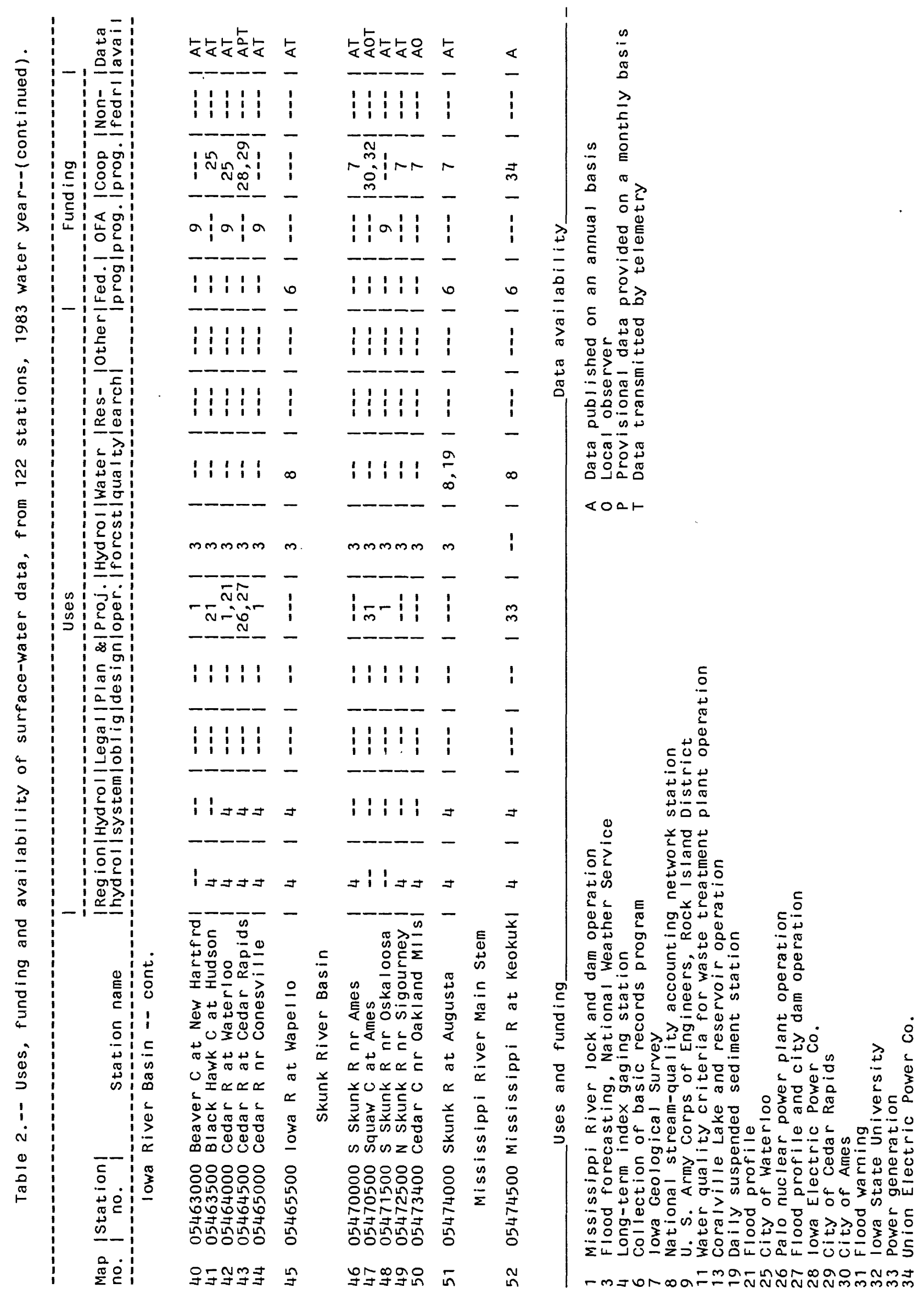




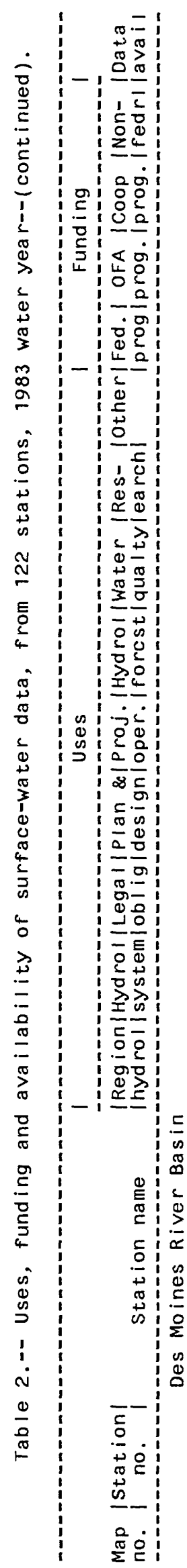

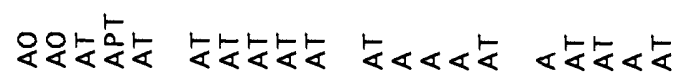

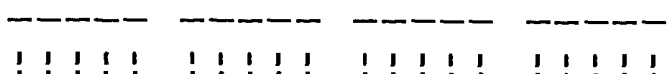

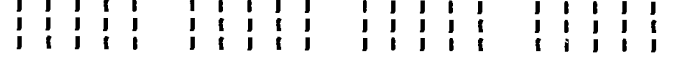
-

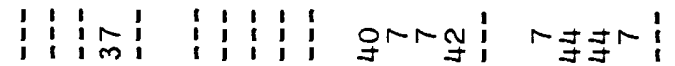
- - - - - - - - - - - - - -

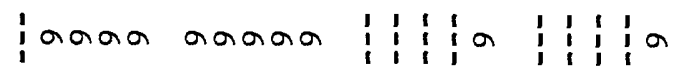
-ー- - - - - - - - - - -

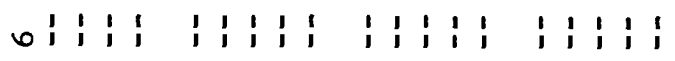
-ーーー - - - - - - - - -

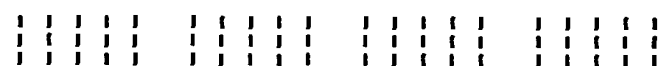
-

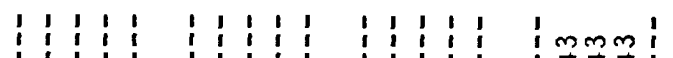
-ー-ー 1'iti itioi íi'i immol -ーーー - - - - - - - ーーーー

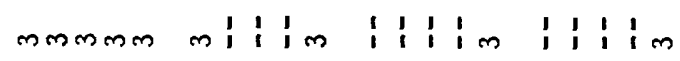

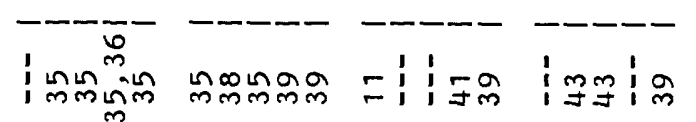
-

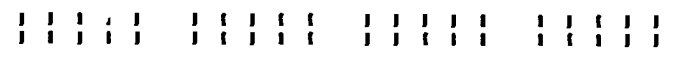

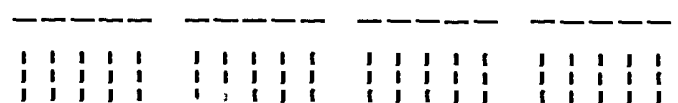

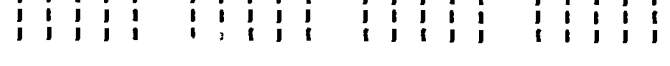

i i is 9i i i i i i ai iag ai i i iagia ai iaz 二艺可市

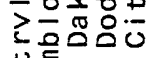
is

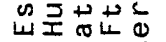

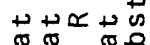

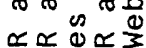
is os. ns Q 을을 क क w क क 은용ㅇㅇㅇ

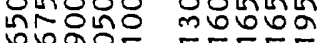

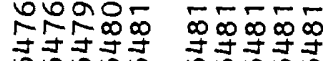

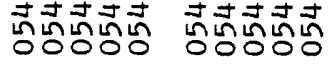

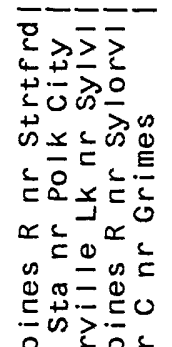

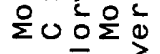
काति

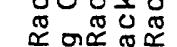

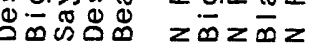
은우우 냉요요

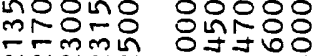
พลN $\infty$

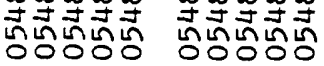
กีนีที่ํำ
ตึกิำธิ์

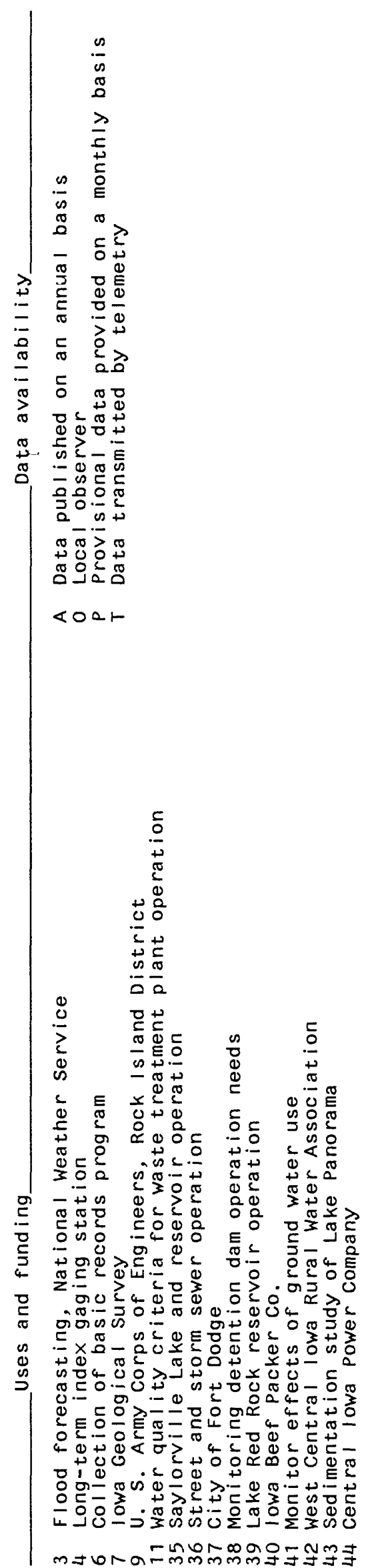




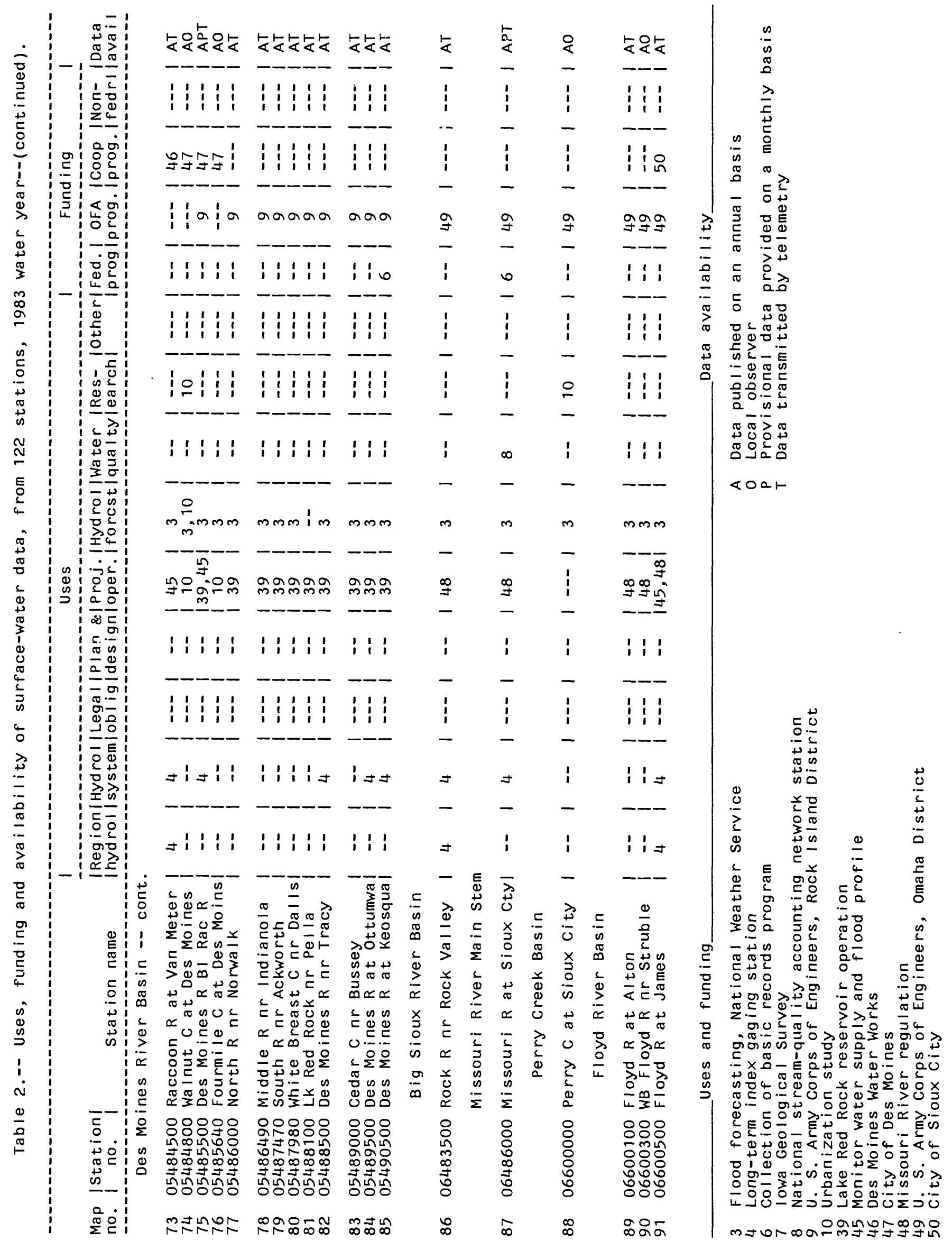




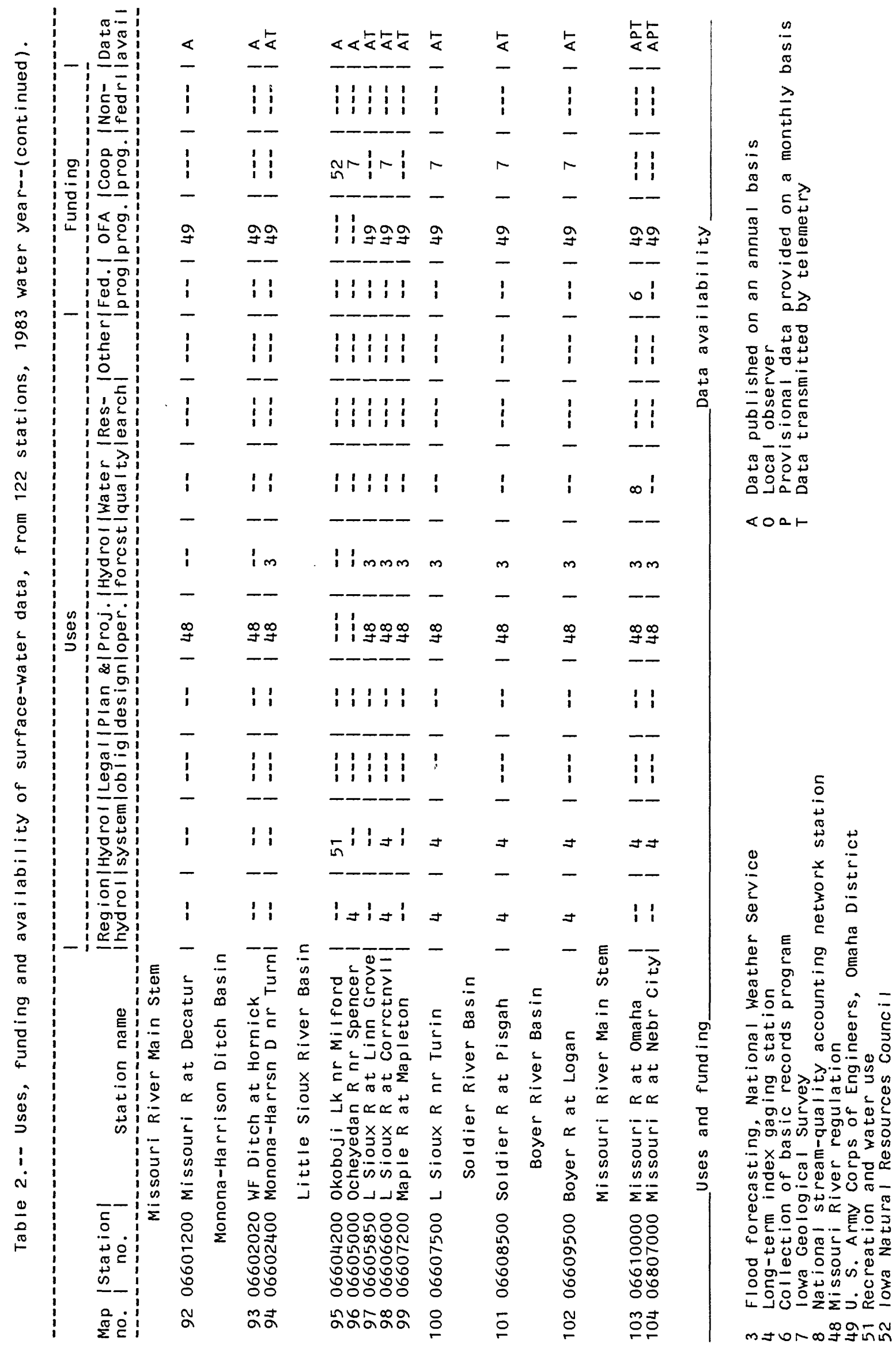




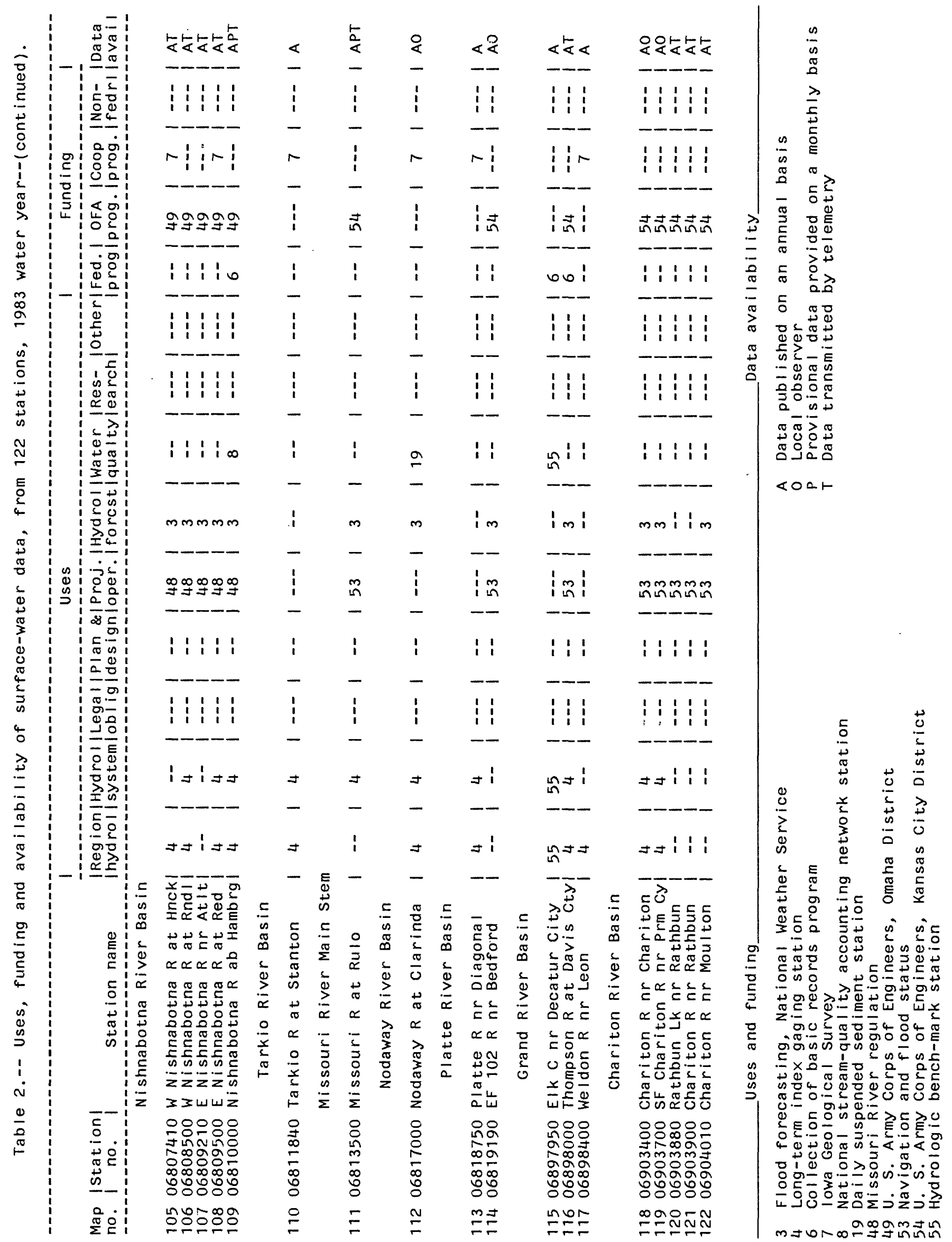




\section{Project Operation}

Gaging stations in this category are used, on an ongoing basis, to assist water managers in making operational decisions such as reservoir releases, hydropower operations, or diversions. The project-operation use generally implies that the data are routinely available to the operators on a rapid reporting basis. For projects on large streams, data may be needed only every few days.

There are 91 stations in the lowa program that are used in this manner. Forty-five of these are used to aid operators in the management of reservoirs and control structures that are part of multipurpose projects of flood control, recreation, navigation and low-flow augmentation.

\section{Hydrologic Forecasts}

Gaging stations in this category are regularly used to provide information for hydrologic forecasting by agencies other than the $U$. S. Geological Survey. These might be flood forecasts for a specific river reach, or periodic (daily, weekly, monthly, or seasonal) flow-volume forecasts for a specific site or region. The hydrologic-forecast use generally implies that the data are routinely available to the forecasters on a rapid reporting basis. On large streams, data may be needed only every few days.

Stations in the lowa program that are included in the hydrologic-forecast category are those used for flood forecasting and for forecasting inflows to reservoirs that are a part of the flood control systems. Data are used by the National Weather Service's Flood Forecast Center in Kansas City, Missouri, and the U.S. Army Corps of Engineers to predict flood flows and reservoir inflows at downstream sites. Additionally, the National Weather Service uses the data at some stations as input to longer-range prediction models of the probability of rainfall and snowmelt floods.

$$
\text { Water-Quality Monitoring }
$$

Gaging stations where regular water-quality or sediment-transport monitoring is being conducted and where the availability of streamflow data contributes to the utility or is essential to the interpretation of the water-quality or sediment data are designated as water-quality-monitoring stations.

One such station in the 1983 water-year program is a designated bench-mark station, 9 are daily sediment stations, and 7 are National Stream QualityAccounting Network (NASQAN) stations. Water-quality samples from bench-mark stations are used to indicate water-quality characteristics of streams that have been and probably will continue to be relatively free of the effects of man. NASQAN stations are part of a countrywide network designed to assess waterquality trends of significant streams.

\section{Research}

Gaging stations in this category are operated for a particular research or water-investigations study. Typically, these are only operated for a few years. One station in the lowa program is used in the study of urbanization on a small watershed (Crow Creek near Bettendorf, (05422470). 
The four sources of funding for the streamflow-data program are:

1. Federal program.--Funds that have been directly allocated to the $U$. $S$. Geological Survey.

2. Other Federal Agency program.--Funds that have been trans-ferred to the U. S. Geological Survey by other Federal agencies.

3. State-Federal cooperative program.--Funds that come jointly from U. S. Geological Survey cooperative-designated funding and from a non-Federal cooperating agency. Cooperating-agency funds may be in the form of direct services or cash.

4. Other non-Federal.--Funds that are provided entirely by a non-Federal agency or a private concern under the auspices of a Federal agency. In this study, funding from municipal and private concerns was limited to operation of water supply, waste-treatment projects, and legal requirements for water use. Funds in this category are not matched by U. S. Geological Survey cooperative funds.

In all four categories, the identified sources of funding pertain only to the collection of streamflow data; sources of funding for other activities, particularly collection of water-quality samples at the gaging station, may not necessarily be the same as those identified herein. Twenty-six entities currently are contributing funds to the lowa stream-gaging program.

\section{Frequency of Data Availability}

Data availability refers to the times at which the streamflow data may be provided to the users. In this category, four distinct possibilities exist. Data can be provided by direct-access telemetry equipment for immediate use, by periodic release of provisional data, by local observer, or in publication format through the annual data report (Water Resources Data for lowa, 1982). These four categories are designated $T, P, O$, and $A$, respectively, in table 2 . In the current lowa program, data for all 122 stations are made available through the annual report, data from 76 stations are available by telemetry, and data are released on a provisional basis at 9 stations. Thirteen stations have local observers to report current gage readings as needed.

\section{Data-Use Presentation}

Information about data use, funding, and availability for the 122 stations operated in the basic surface-water program are listed in table 2 . This list of stations include 4 reservoir, 4 lake, 3 stage only and 1 miscellaneous stations. Footnotes explain the coding for the various categories.

\section{Summary of First Phase of Analysis}

As the data in table 2 indicate, many of the 110 continuous streamflow stations are used to provide data for accounting, project operation, and forecasting. Although these stations may have been established for only one specific purpose, the availability of the data, in itself, has produced other uses of the data, such as definition of regional hydrology and hydrologic systems. There are 25 stations that now provide data for the definition of regional hydrology or hydrologic systems in addition to providing data for the original purpose(s) of 
the stations. If funding for the original purpose(s) either is decreased or discontinued, additonal funds need to be sought to maintain these 25 stations for the purposes of continuing the definition of regional hydrology and hydrologic systems.

There are 21 streams in lowa with drainage areas between 200 and $400 \mathrm{mi}^{2}$ (Larimer, 1957) that have no continuous streamflow data. These streams are in the basins of the Des Moines, lowa, Little Sioux, Nishnabotna, Nodaway, Skunk, Turkey, and Wapsipinicon Rivers. Based on average-flow and low-flow studies (Lara, 1979), the average flows in each of these streams is estimated to be about $100 \mathrm{ft}^{3} / \mathrm{s}$ in all the river basins except the Little Sioux and Rock River basins where the average flow of the streams is estimated to be about $50 \mathrm{ft}^{3} / \mathrm{s}$. This quantity of flow is a valuable resource and needs to be monitored to define regional hydrology. Efforts need to be made to begin collecting continuous-flow data for these streams during the next 5 years.

There are 80 continuous streamflow stations in lowa that are used to provide data to the National Weather Service for hydrologic forecasting (table 2). Telemetry equipment has been installed and are maintained in 11 of these stations by the National Weather Service. The Geological Survey maintains the basic station equipment and collects, processes, and transmits the data needed by the National Weather Service for their forecasts.

More research to determine: effects of urbanization, time of travel, flow routing, and streamflow losses is needed in lowa. During the 1983 water year, only one station (Crow Creek at Bettendorf, 05422470, table 2) was funded for urbanization studies. Short-term studies have been made in two other small basins in urbanized areas in the past few years, but financial support has been small. Because of the increasing concern about the effects of urbanization on surface-water quantity and quality, additional studies in urban areas need to be started.

Time-of-travel studies have been made on the Missouri River (Bowie and Petri, 1979), but none on interior streams in lowa. Because of the increasing concern of the effects of substances, particularly chemicals, that might be accidently spilled or discharged into streams on downstream uses of the wate, time-oftravel studies need to be made on all major streams in lowa.

Flow-routing studies as discussed in the second phase of the analysis show that simulated data does not meet accuracy requirements for most uses. Additional studies may define acceptable limits that could be applied for some purposes.

Brief studies on streamflow losses on the Turkey River, Little Sioux River and Missouri River indicate that losses do exist. Thorough studies using equipment and techniques capable of measuring streamflow within 1 percent are needed to define the amount and location of losses in these rivers and possibly in other streams.

The first phase of the analysis indicates that data collection, in many instances for an increasing number of uses, needs to be continued at all of the current (1983) 110 continuous streamflow stations. All 110 continuous streamflow stations were used in the second and third phases of the analysis. 


\section{ALTERNATIVE METHODS OF DEVELOPING STREAMFLOW INFORMATION}

The second phase of the analysis of the stream-gaging program was to investigate alternative methods of providing daily streamflow information in lieu of operating continuous streamflow stations. The objective of this phase of the analysis is to identify gaging stations where alternative technology, such as flowrouting or statistical methods, could provide information about daily mean streamflow in a more cost-effective manner than operating the continuous streamflow stations. No guidelines exist concerning suitable accuracies for particular uses of the data; therefore, judgment was required in deciding whether the accuracy of the estimated daily flows would be suitable for the intended purpose. The uses of data from a station will affect whether or not that station could be discontinued. For example, those stations for which flood hydrographs are required in a real-time sense, such as hydrologic forecasts and project operation, are not candidates for the alternative-method approach. Likewise, there might be a legal obligation to operate an actual gaging station that would preclude using alternative methods. The primary candidates for alternative methods are stations that are operated upstream or downstream of other stations on the same stream. The accuracy of the estimated streamflow at these sites may be suitable because of the significant redundancy of flow information between sites. Similar watersheds, located in the same physiographic and climatic area, also may have potential for alternative methods.

Selected continuous streamflow stations in six river basins in lowa were analyzed to determine their potential as alternative method sites. A brief description of the alternative methods considered in this study are presented in this section.

Because of the short duration of this analysis, only two methods were considered. Desirable attributes of a proposed alternative method are: (1) The proposed method needs to be computer oriented and easy to apply, (2) The proposed method needs to have an available interface with the $U$. S. Geological Survey's WATSTORE Daily-Values File (Hutchison, 1975) in order to facilitate the calibration of the proposed method, (3) the proposed method needs to be technically sound so it will be able to provide data of suitable accuracy, and be generally acceptable to the hydrologic community, and (4) ine proposed method needs to permit easy evaluation of the accuracy of the simulated streamflow records. The above criteria were used to select two alternative methods for cosideration, a flow routing model and multiple regreession analysis.

\section{Description of Flow-Routing Model}

Hydrologic flow-routing methods use the law of conservation of mass and the relationship between the storage in a reach and the outflow from the reach. The hydraulics of the system are not considered. The method usually requires only a few parameters and treats the reach in a lumped sense without subdivision. The input usually is a discharge hydrograph at the upstream end of the reach and the output, a discharge hydrograph at the downstream end. Several different types of hydrologic routing are available such as Muskingum, Modified Puls, Kinematic Wave, and the unit-response flow-routing method. The latter method was selected for this analysis. This method uses two techniques--storage continuity (Sauer, 1973) and diffusion analogy (Keefer, 1974; Keefer and McQuivey, 1974). These concepts are discussed below. 
The unit-response flow-routing method was selected because it fulfilled the criteria noted above. Computer programs for the unit-response method can be used to route streamflow from one or more upstream locations to a downstream location. Downstream hydrographs are produced by the convolution of upstream hydrographs with their appropriate unit-response functions. This method can only be applied at a downstream station where an upstream station exists on the same stream. An advantage of this model is that it can be used for regulated stream systems. Reservoir-routing techniques are included in the model so flows can be routed through reservoirs if the operating rules are known. Calioration and verification of the flow-routing model is achieved using historic upstream and downstream hydrographs and estimates of tributary inflows. The convolution subroutine of the model treats a stream reach as a linear one-dimensional system in which the system output (downstream hydrograph) is computed by multiplying (convoluting) the ordinates of the upstream hydrograph by the unit-response function and lagging them appropriately. The model has the capability of combining hydrographs, multiplying a hydrograph by a ratio, and changing the timing of a hydrograph. In this analysis, the model is only used to route an upstream hydrograph to a downstream point. Routing can be accomplished using hourly data, but only daily data are used in this analysis.

Three options are available for determining the unit-(system) response function. Selection of the appropriate option depends primarily on the variability of wave celerity (traveltime) and disperion (channel storage) throughout the range of discharges to be routed. Adequate routing of daily flows usually can be accomplished using a single unit-response function (linearization about a single discharge) to represent the system response. However, if the routing coefficients vary significantly with discharge, linearization about a low-range discharge results in overestimated high flows that arrive late at the downstream site; whereas, linearization and a high-range discharge results in low-range flows that are underestimated and arrive too soon. A single unit-response function may not provide acceptable results in such cases. Therefore, the option of multiple linearization (Keefer and McQuivey, 1974), which uses a family of unit-response functions to represent the system response, is available.

Determination of the system's response to the input at the upstream end of the reach is not the total solution for most flov-routing problems. The convolution process makes no accounting of flow from the intervening area between the upstream and downstream locations. Such flows may be totally unknown or estimated by some combination of gaged and ungaged flows. An estimating technique that should prove satisfactory in many instances is the multiplication of known flows at an index gaging station by a factor (for example, a drainage-area ratio).

The objective in either the storage-continuity or diffusion analogy flow-routing method is to calibrate two parameters that describe the storage-discharge relationship in a given reach and the traveltime of flow passing through the reach. In the storage-continuity method, a response function is derived by modifying a translation-hydrograph technique developed by Mitchell (1962) to apply to open channels. A triangular pulse (Sauer, 1973) is routed through reservoir-type storage and then transformed by a summation-curve technique to a unit response of desired duration. The two parameters that describe the routing reach are Ks, a storage coefficient that is the slope of the storage-discharge relation, and Ws, the translation-hydrograph time base. These two parameters determine the shape of the resulting unit-response function. 
In the diffusion-analogy theory, the two parameters requiring calibration in this method are Ko, a wave-dispersion or damping coefficient, and Co, the floodwave celerity. Ko controls the spreading of the wave (analogous to $\mathrm{Ks}$ in the storage-continuity method) and Co controls the traveltime (analogous to Ws in the storage-continuity method). In the single-linearization method, only one Ko and Co value are used. In the multiple-linearization method, Co and Ko are varied with discharge so a table of wave celerity (Co) versus discharge (Q) and a table of dispersion coefficient (Ko) versus discharge (Q) are used.

The coefficients Co and Ko are determined from the following equations:

$$
\begin{aligned}
& C_{0}=\begin{array}{cc}
1 & d Q_{0} \\
-W_{0} & d Y_{0}
\end{array} \\
& K_{0}=\frac{\text { Qo }}{2 \text { SoWo, }},
\end{aligned}
$$

where

Wo is the average channel width for the reach, So is the channel slope over the reach, Qo is the discharge for which the initial values of Co and Ko were linearized, and $Y_{0}$ is the average depth in the reach for Qo.

The derivative dQo/dYo therefore represents the slope of the stage-discharge relation.

In both the storage-continuity and diffusion-analogy methods, the two parameters are calibrated by trial and error. The analyst needs to decide if suitable parameters have been der,ved by comparing the simulated discharge to the measured discharge.

\section{Description of Regression Analysis}

Simple- and multiple-regression techniques also can be used to estimate daily flow records. Regression equations can be computed that relate daily flows at a single station to daily flows at a combination of upstream, downstream, and tributary stations. This statistical method is not limited, like the flow-routing method, to stations where an upstream station exists on the same stream. The explanatory variables in the regression analysis can be stations from different watershed, or downstream and tributary watersheds. The regression method has many of the same attributes as the flow-routing method in that it is easy to apply, provides indices of accuracy, and is generally accepted as a good tool for estimation. The theory and assumptions of regression analysis are described in several textbooks such as Draper and Smith (1966) and Kleinbaum and Kupper (1978). The application of regression analysis to hydrologic problems is described and illustrated by Riggs (1973) and Thomas and Benson (1970). Only a brief description of regression analysis is provided in this report. 
A linear regression model of the following form was used for estimating daily mean discharges:

where

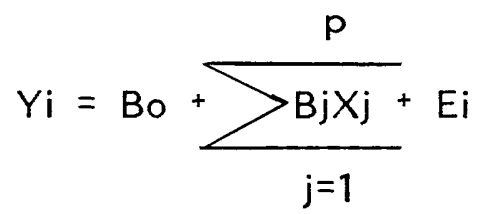

$\begin{aligned} \mathrm{Yi}_{\mathrm{i}} & =\text { daily mean discharge at station } \mathrm{i} \text { (dependent variable), } \\ \mathrm{Xj} & =\begin{array}{l}\text { daily mean discharges at nearby stations (explanatory } \\ \text { variables), }\end{array}\end{aligned}$

Bo and $\mathrm{Bj}=$ regression constant and coefficients, and

$\mathrm{Ei}=$ the random error term.

The above equation is calibrated ( $B o$ and $B j$ are estimated) using measured values of $Y_{i}$ and $X j$. These measured daily mean discharges can be retrieved from the WATSTORE Daily Values File. The values of $X j$ may be discharges measured on the same day as discharges at station $i$ or may be for previous or future days, depending on whether station $j$ is upstream or downstream of station $i$. Once the equation is calibrated and verified, future values of $Y_{i}$ are estimated using measured values of $\mathrm{Xj}$. The regression constant and coefficients (Bo and $\mathrm{Bj}$ ) are tested to determine if they are significantly different from zero. The regression equation needs to be calibrated using one period of time and then verified or tested using a different period of time to obtain a measure of the true predictive accuracy. Both the calibration and verification period needs to be representative of the range of flows that could occur at station $i$. The equation can be verified by: (1) plotting the residuals $\mathrm{Ei}$ (difference between simulated and measured discharges) aga,nst the dependent and all explanatory variables in the equation, and (2) plotting the simulated and measured discharges versus time. These tests are intended to identifyify if: (1) The linear model is appropriate or whether some transformation of the variables is needed, and (2) there is any bias in the equation such as overestimating low flows. These tests might indicate, for example, that a logarithmic transformation is desirable, that a nonlinear regression equation is appropriate, or that the regression equation is biased in some way. In this report these tests indicated that a linear model with $Y i$ and $X_{j}$, in cubic feet per second was appropriate.

\section{Selection of Continuous Streamflow Stations for Their Potential for Alternative Methods}

The feasibility of providing daily flow information using alternative methods was investigated for six river basins in lowa. These basins were selected because they contained continuous streamflow stations at points where alternative methods of estimating daily flows appear to be possible. A second criterion for selecting these basins was to obtain as wide a geographical coverage as possible. The six basins selected for this study are the Cedar, Des Moines, Floyd, Raccoon, and South Skunk river basins (Fig.3). 


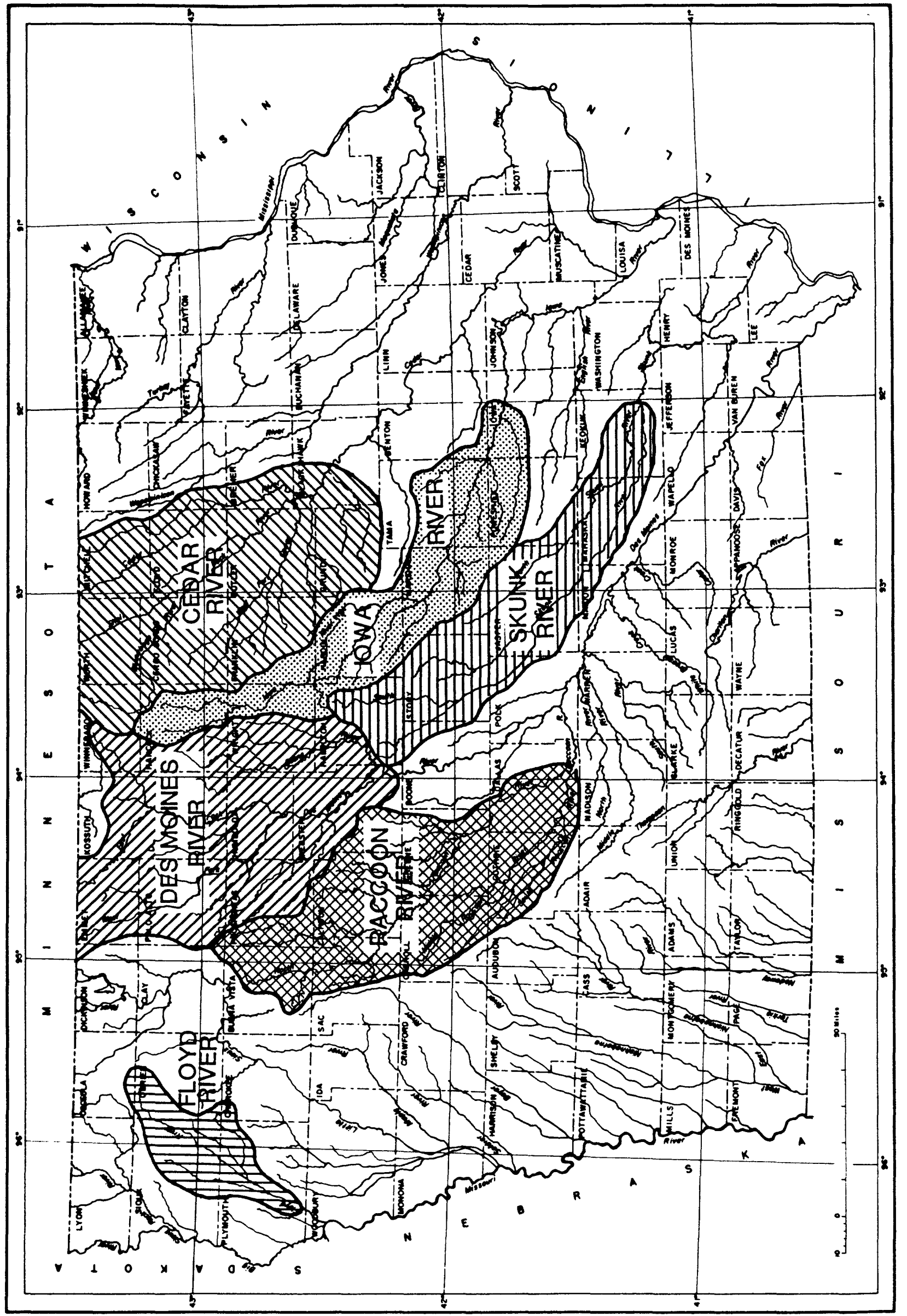

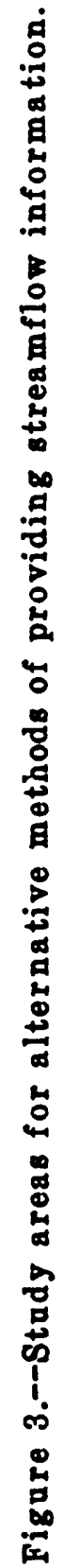




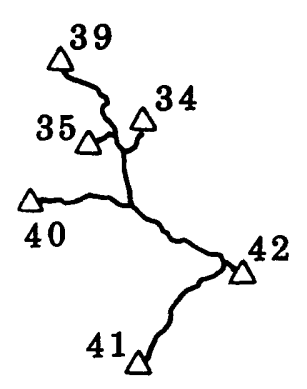

Cedar River

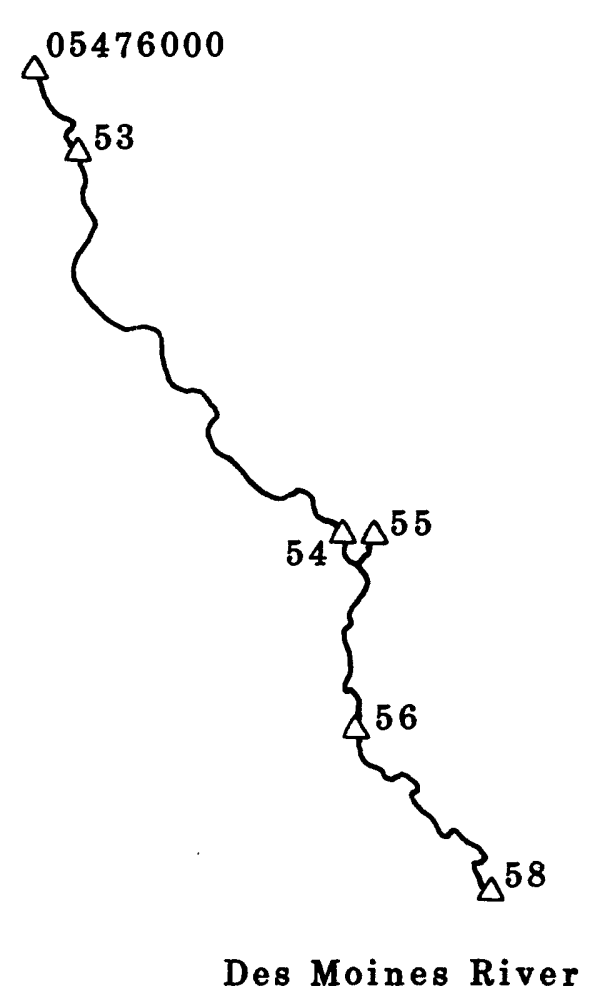

Figure 4.--Study areas in the Cedar and Des Moines River basins. 


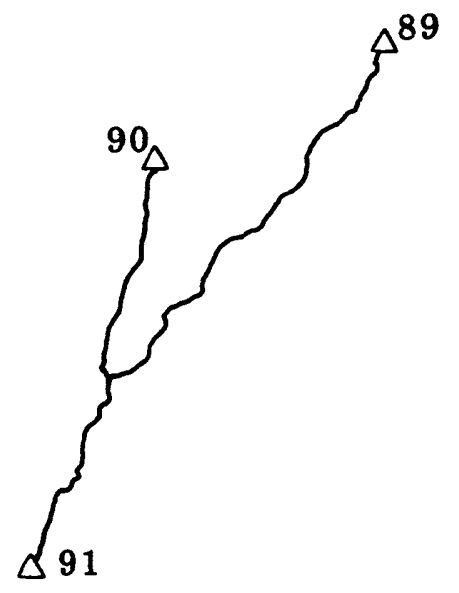

Floyd River

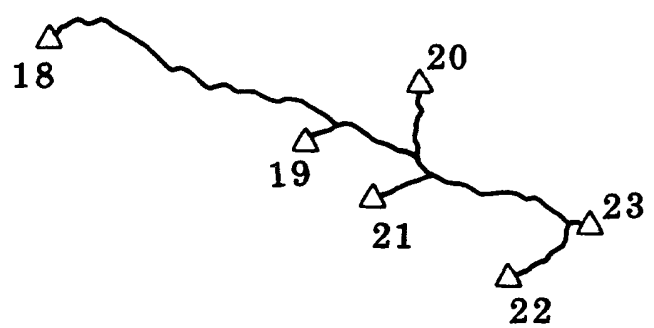

Iowa River

Figure 5.--Study areas in the Floyd and Iowa River basins. 


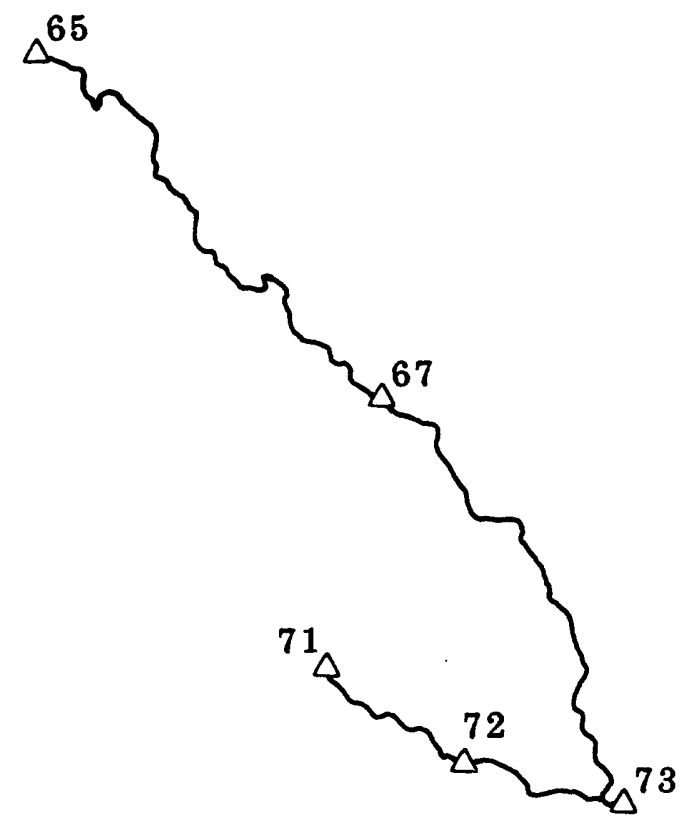

Raccoon River

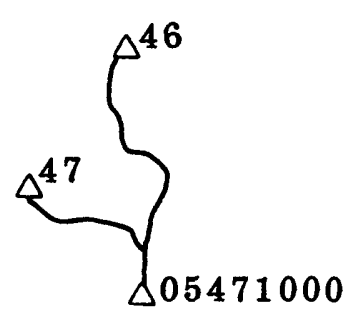

Skunk River

Figure 6.--Study areas in the Raccoon and Skunk River basins. 
Table 3. -- Selected characteristics used in the flow-routing studies

\begin{tabular}{|c|c|c|c|c|c|c|c|}
\hline Station & Basin & $\begin{array}{l}\text { Qo } \\
\mathrm{ft} / \mathrm{s}\end{array}$ & $\begin{array}{l}\text { Wo } \\
\mathrm{ft}\end{array}$ & $\begin{array}{l}\text { So } \\
\mathrm{ft} / \mathrm{ft}\end{array}$ & $\begin{array}{l}\mathrm{dQ} / \mathrm{dY} \\
\mathrm{ft} / \mathrm{s}\end{array}$ & $\mathrm{ft} / \mathrm{s}$ & $\mathrm{ft} / \mathrm{s}$ \\
\hline $\begin{array}{l}34 \\
35 \\
39 \\
40 \\
41 \\
46 \\
47 \\
*\end{array}$ & $\begin{array}{l}\text { Cedar } \\
\text { Cedar } \\
\text { Cedar } \\
\text { Cedar } \\
\text { Cedar } \\
\text { S. Skunk } \\
\text { S. Skunk } \\
\text { Des Moines }\end{array}$ & $\begin{array}{c}800 \\
462 \\
887 \\
189 \\
163 \\
147 \\
117 \\
273\end{array}$ & $\begin{array}{c}600 \\
450 \\
600 \\
150 \\
150 \\
132 \\
132 \\
198\end{array}$ & $\begin{array}{c}0.00056 \\
0.00068 \\
0.00052 \\
0.00080 \\
0.00074 \\
0.00069 \\
0.00095 \\
0.00053\end{array}$ & $\begin{array}{c}1050 \\
120 \\
175 \\
126 \\
107 \\
272 \\
284 \\
271\end{array}$ & $\begin{array}{l}1.75 \\
0.27 \\
0.29 \\
0.84 \\
0.76 \\
2.06 \\
2.15 \\
3.67\end{array}$ & $\begin{array}{c}1190 \\
755 \\
1421 \\
788 \\
689 \\
807 \\
467 \\
132\end{array}$ \\
\hline \multicolumn{8}{|c|}{$\begin{array}{l}\text { * } 5-4760 \text { Gaging station in Minnesota } \\
\text { Qo is the stream discharge in cubic feet per second } \\
\text { Wo is the average channel width for the study reach in feet } \\
\text { So is the average bed slope in feet per feet } \\
\text { Yo is the average depth of flow in feet } \\
\text { Co is the flood wave celerity in feet per second } \\
\text { Ko is the wave dispersion or damping coefficient in feet squared per second }\end{array}$} \\
\hline
\end{tabular}

Table 4. - Summary of flow-routing results and comparison between measured and simulated flows

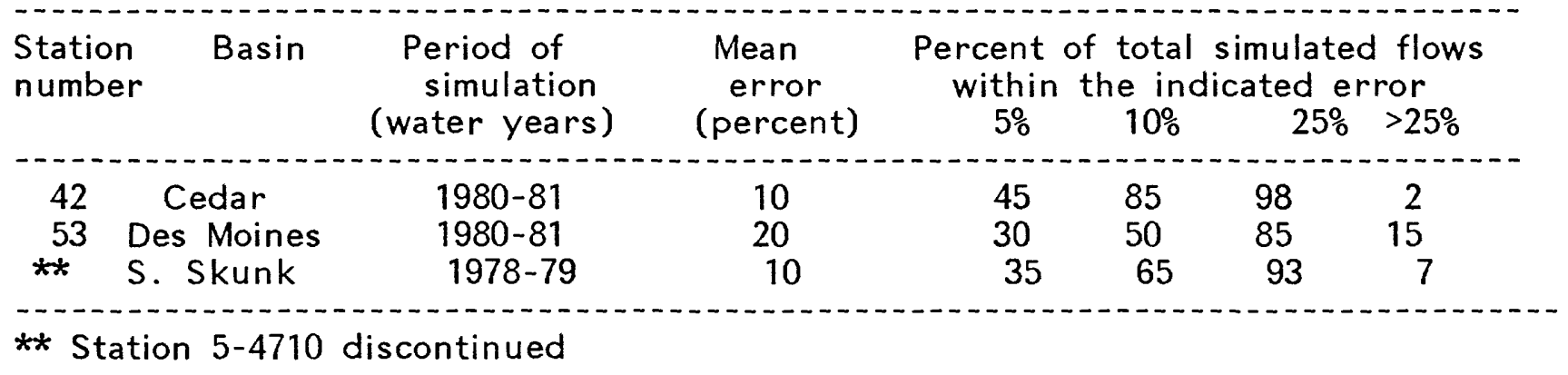


Because of time and budget constraints, only a representative number of stations was selected for this study. The District needs to continue to search, on a systematic basis, for stations where alternative methods could be applicable.

For the sake of brevity only the final results of model calibration and simulation are presented in this report. The details of estimating model parameters, techniques of model calibration and verification, methods for estimating intervening flows, and methods for selecting optimal estimators, have been documented and are available for reference at the District Office in lowa City.

Both flow-routing and regression techniques were used to evaluate selected stations in the Cedar River (Fig. 4), Des Moires River (Fig. 5), and South Skunk River(Fig. 5) basins. Only regression techniques were used to evaluate selected stations in the Floyd River (Fig.6), lowa River(Fig.4), and Raccoon River (Fig.6) basins.

The objective of the flow-routing analyses were to determine (1) If station 42 in the Cedar River Basin and station 53 in the Des Moines River basin could be discontinued, and (2) if a previous decision to discontinue station 05471000 in the South Skunk River basin was valid. Prior to its being discontinued in 1979 at the request of the cooperator, daily flows at station 05471000 were used by local authorities for a number of water management activities. It was assumed that daily flows of sufficient accuracy could be estimated by using the daily flows at stations 46 and 47 . Aspects of the flow-routing analyses are summarized in tables 3 and 4. Selected reach characteristicsare summarized in table 3 and the results of the analyses are summarized in table 4 . Regression models were developed for all the stations mentioned above, shown in figures 4-6, however, only the results for selected stations with the smallest errors in each of the basins are presented in table 5. The table includes the predictive equation for streamflow at each station and a comparison between measured and simulated streamflow.

The results of the analysis indicated that the simulated streamflows are not accurate enough to warrant using either alternative techniques in lieu of operating the gaging stations. However, it should be emphasized that these are preliminary results.

Based on these preliminary results:

1. It may be possible to use an alternative method for determining styreamflow in lieu of operating stations 42 in the Cedar River basin, but this possibility does not appear to exist for the other stations in the basin that were analyzed.

2. It appears that station 53 in the Des Moines River basin can not be discontinued, however, results of the regression analysis for station 56 in the same basin indicate that it may be possible to use an alternative method for determining streamflow in lieu of operating this station. All other stations in the basin that were analyzed need to be continued.

3. It appears that station 05471000 in the South Skunk River basin should not have been discontinued. Although the results obtained by using the flow-routing model appear to be slightly better (mean error 9.7 percent) than the results from the regression analysis (mean error 12 percent), neither are accurate enough to justify discontinuing the station. 


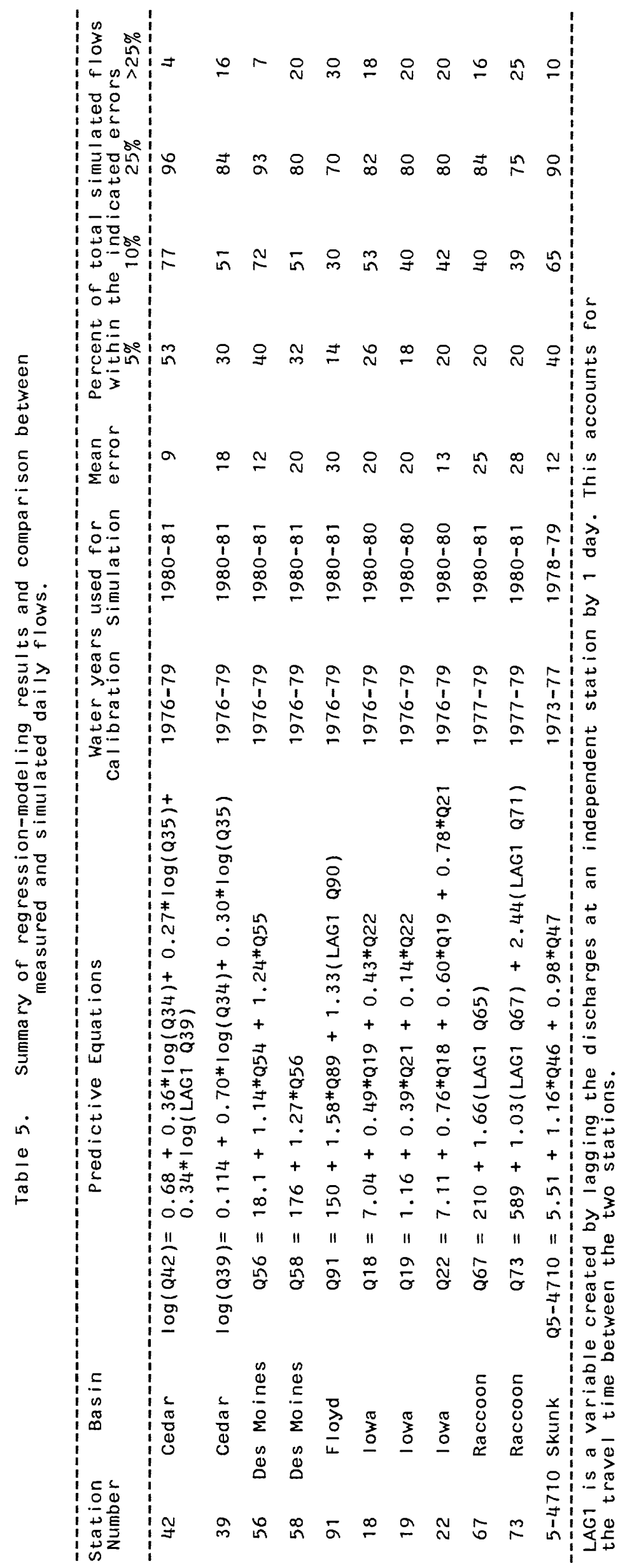


4. No stations in the Floyd River, lowa River, and Raccoon River basins can be discontinued at this time. It may be possible to decrease the errors in the preliminary results by 50 percent, but even then it is likely that the estimated flows would not meet the accuracy requirements.

\section{Summary of the Second Phase of the Analysis}

In general the data simulated by using the flow-routing and regression methods for the stations included in this study did not meet the accuracy needed to consider these methods as alternatives to operating gaging stations. However, as a result of this study, the three gaging stations with significant potential as alternative method sites that have been identified are:

1. Cedar River at Waterloo (station 42).

2. Des Moines River at Fort Dodge (station 56).

3. South Skunk River below Squaw Creek near Ames (station 05471000, discontinued).

The District should study these sites in more detail. Final decisions regarding these gaging stations will be made after the results of the additional studies have been evaluated and discussed with the appropriate cooperating agencies.

If an acceptable alternative method can not be developed for the site of the former gaging station in the South Skunk River basin, then the District needs to take the necessary steps to reactivate the gaging station or to establish a new station downstream from the point of discharge of effluent from the waste treatment plant at Ames.

The District also needs to continue with the identification of gaging stations in other basins where alternative methods could be used. In summary, all the stations considered in this step of the analysis need to be continued and were included in the third and final phase of the analysis.

\section{COST-EFFECTIVE RESOURCE ALLOCATION}

\section{Introduction to Kalman-Filtering for Cost-Effective}

\section{Resource Allocation (K-CERA)}

A set of techniques called K-CERA were developed by Moss and Gilroy (1980) to study the cost-effectiveness of networks of stream gages. The original application of the technique was to analyze a network of stream gages operated to determine water consumption in the Lower Colorado River Basin (Moss and Gilroy, 1980). Because of the water balance nature of that study, the minimization of the total variance of errors of estimation of annual mean discharges was chosen as the measure of effectiveness of the network. This total variance is defined as the sum of the variances of errors of mean annual discharge at each site in the network. This measure of effectiveness tends to concentrate stream-gaging resources on the large rivers and streams where discharge and, consequently, potential errors are greatest. Although this may be acceptable for a waterbalance network, considering the many uses of data collected by the $U$. $S$. Geological Survey, concentration of effort on large rivers and streams is undesirable and inappropriate. 


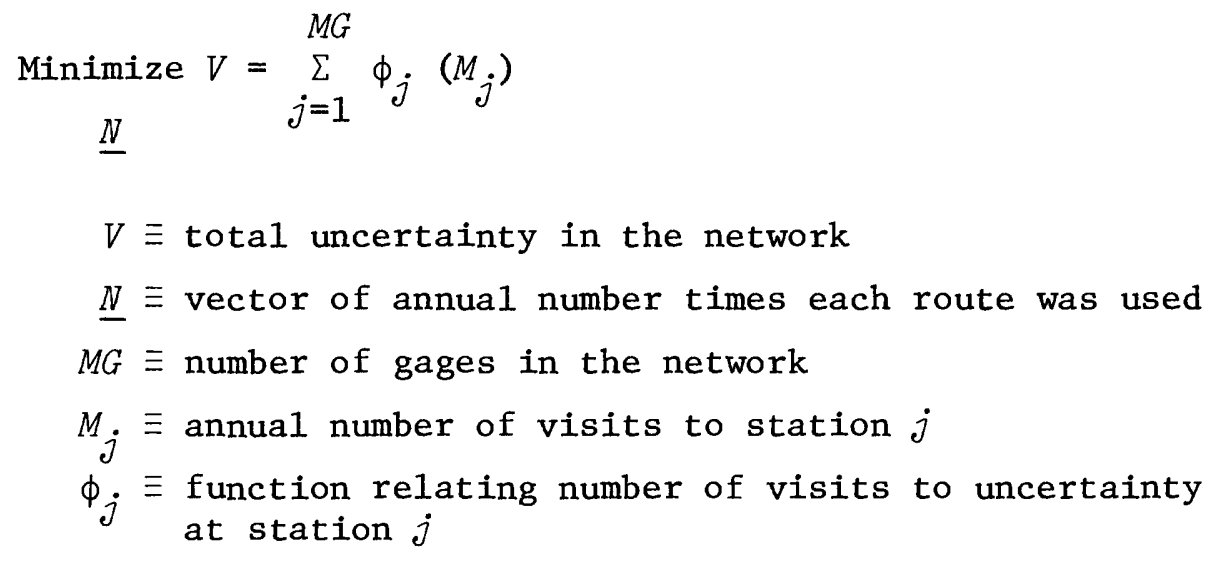

Such that

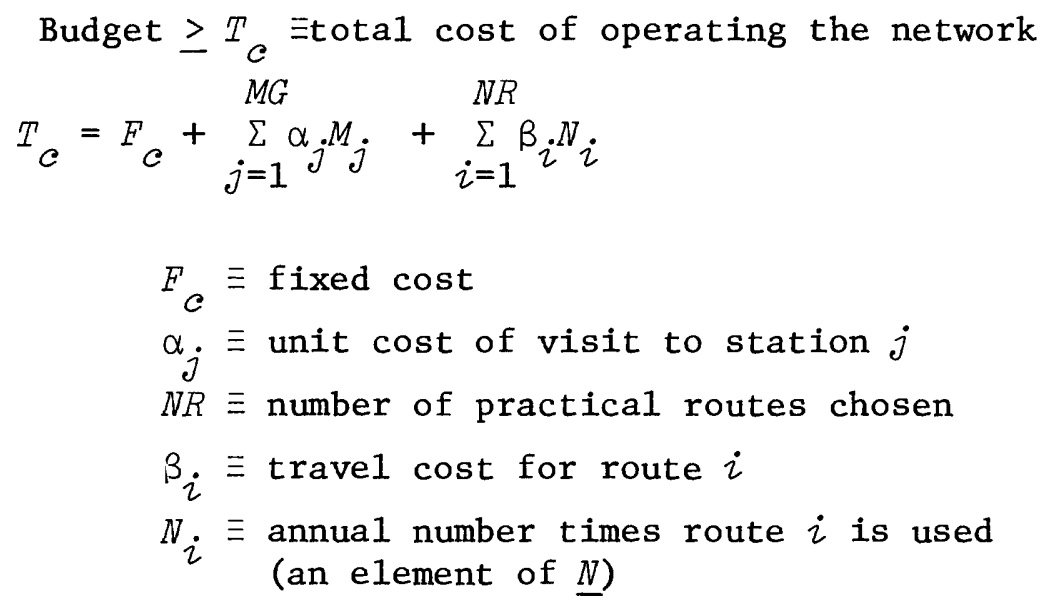

and such that

$$
\begin{aligned}
M_{j} \geq & \lambda_{j} \\
& \lambda_{j} \equiv \text { minimum number of annual visits to station } j
\end{aligned}
$$

Figure 7.-Mathematical programing form of the optimization of the routing of hydrographers. 


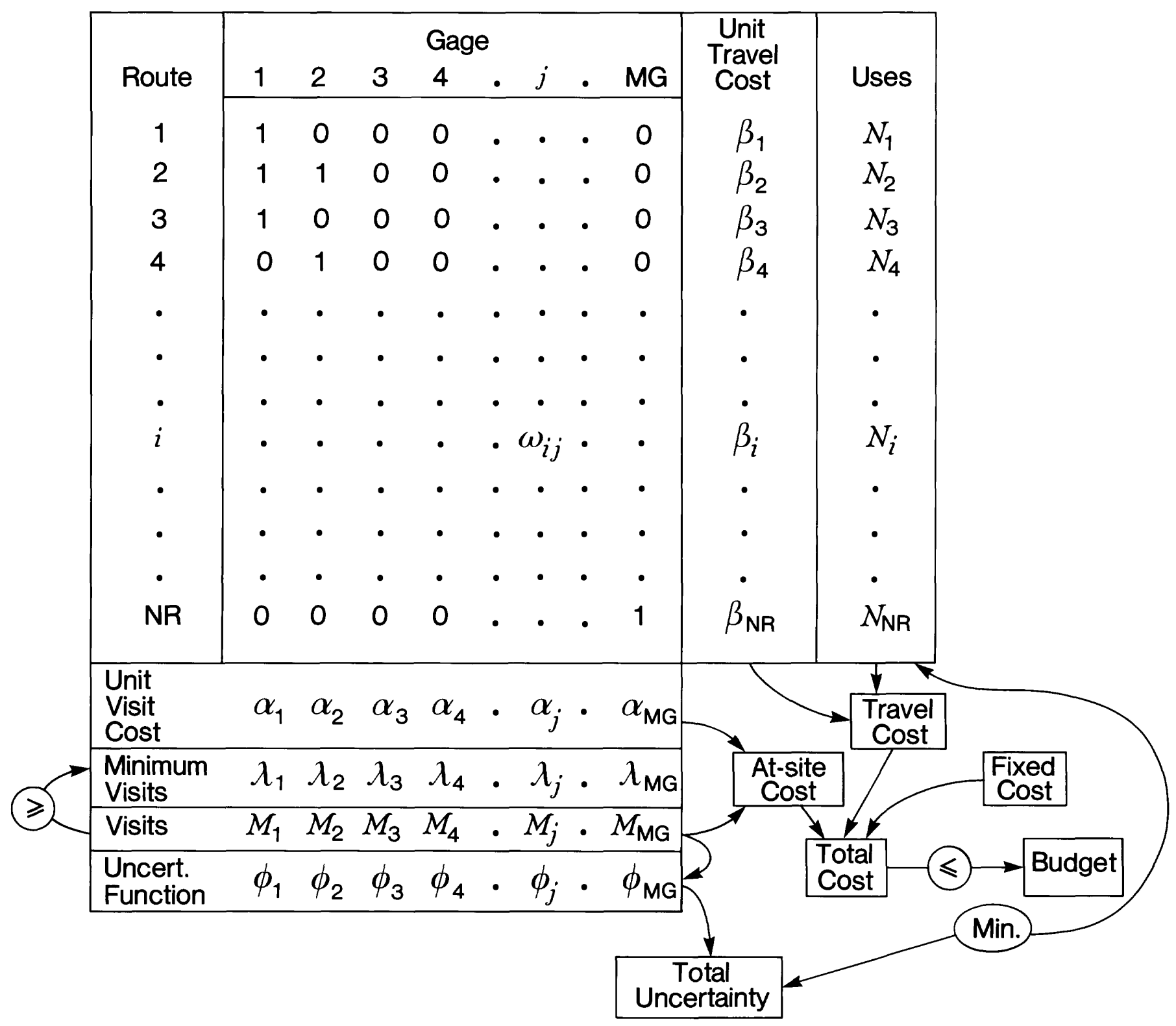

Figure 8.-Tabular form of the optimization of the routing of hydrographers. 
The original version of K-CERA was therefore altered to include as optional measures of effectiveness the sums of the variances of errors of estimation of the following streamflow variables; annual mean discharge, in cubic feet per second; annual mean discharge, in percent; average instantaneous discharge, in cubic feet per second; or average instantaneous discharge, in percent (Fontaine and others, 1983). The use of percentage errors effectively gives equal weight to large and small streams. In addition, instantaneous discharge is the basic variable from which all other streamflow data are derived. For these reasons, this study used the K-CERA techniques with the sums of the variances of the percentage errors of the instantaneous discharges at continuously gaged sites as the measure of the effectiveness of the data-collection activity.

The original version of K-CERA also did not account for error contributed by missing stage or other correlative data that are used to compute streamflow data. The probabilities of missing correlative data increase as the period between service visits to a stream gage increases. A procedure for dealing with the missing record has been developed (Fontaine and others, 1983) and was incorporated into this study.

Brief descriptions of the mathematical program used to minimize the total error variance of the data-collection activity for given budgets and of the application of Kalman filtering (Gelb, 1974) to the determination of the accuracy of a streamgaging record are presented by Fontaine and others (1983). For more detail on either the theory or the applications of the K-CERA model, see Moss and Gilroy (1980) and Gilroy and Moss (1981).

\section{Description of Mathematical Program}

The program, called "The Traveling Hydrographer," attempts to allocate among stream gages a predefined budget for the collection of streamflow data in such a manner that the field operation is the most cost-effective possible. The measure of effectiveness is discussed above. The set of decisions available to the manager is the frequency of use (number of times per period) of each of a number of routes that may be used to service the stream gages and to make discharge measurements. The range of options within the program is from zero use to daily use for each route. A route is defined as a set of one or more stream gages and the least cost travel that takes the hydrographer from his base of operations to each of the gages and back to base. A route will have associated with it an average cost of travel and average cost of servicing each stream gage visited along the way. The first step in this part of the analysis is to define the set of practical routes. This set of routes usually will contain the route to an individual stream gage with that gage as the lone stop and return to the home base so that the individual needs of a stream gage can be considered in isolation from the other gages.

Another step in this part of the analysis is the determination of any special requirements for visits to each of the gages for such things as necessary periodic maintenance, rejuvenation of recording equipment, or required periodic sampling of water-quality data. The minimum number of visits to each gage usually are limited by these special requirements.

The final step is to use all of the above to determine the number of times that each route is used during a year such that: (1) The budget for the network is not exceeded, (2) the minimum number of visits to each station is made, and (3) the total uncertainty in the network is minimized. This step in the form of a mathematical program is presented in figure 7. A tabular presentation of the problem is presented in figure 8. Each of the routes is represented by a row of 
the table and each of the stations is represented by a column. The zero-one matrix defines the routes in terms of the stations that comprise it. A value of 1 in the row indicates that gaging a station will be visited on the route; a value of zero indicates that it will not. The unit travel costs are the per-trip costs of the hydrographer's traveltime and any related per diem and operation, maintenance, and rental costs of vehicles. The sum of the products of the unit travel costs multiplied by the times the route was used is the total travel cost.

The unit-visit cost is comprised of the average service and maintenance costs incurred on a visit to the station plus the average cost of making a discharge measurement. The minimum visit constraints are set for each station. The product of the visits to each station per route and the times the route is used must equal or exceed the minimum visit constraints.

The total cost expended at the stations is equal to the sum of the products of unit cost and number of visits for all stations. The cost of record computation, documentation, and publication is assumed to be affected negligibly by the number of visits to the station and is included in the fixed cost of operating the network. The total cost of operating the network equals the sum of the travel costs, the at-site costs, the fixed cost, and the overhead cost, and needs to be less than or equal to the available budget.

The total uncertainty in the estimates of discharges at all the stations in the network is determined by summing the uncertainty functions evaluated for the total visits to all stations.

As pointed out in Moss and Gilroy (1980), the steepest descent search used to solve this mathematical program does not guarantee a true optimum solution. However, the locally optimum set of values obtained with this technique specify an efficient strategy for operating the network, which may be the true optimum strategy. The true optimum strategy cannot be guaranteed without testing all undominated, feasible strategies.

A detailed description of the uncertainity function (Fontaine and others, 1983) and a similar description of for the method for deriving the relationship of visit frequency to lost record (Moss, 1983), as published in the report of the pilot study of cost effectiveness in Maine, are found in the Supplemental Data section of this report.

It is assumed in this study that the differences between the logarithms of the computed discharges and the true discharges at each instance are normally (Gaussian) distributed with a mean of zero and a variance of either $V f, V r$, or $V e$ depending on whether the at-site streamflow recorder was functioning $(f)$, whether the record was reconstructed $(r)$ from another primary source of data, or whether the record was estimated (e) without the aid of other concurrent data. Therefore, the resulting apriori distribution of errors is not normally distributed in terms of the logarithms of discharge data. This lack of normality causes difficulty in interpretation of the resulting errors of estimation, that is, the square root of the uncertainty contained in the streamflow record. If the logarithmic errors were normally distributed, approximately two-thirds of the time the true logarithmic error would be within the range defined by plus and minus one standard error from the mean. The lack of normality caused by the multiple sources of error increases the percentage of errors contained within this range to more than above that of a Gaussian probability distribution of logarithmic errors with the same standard deviation. 
To assist in interpreting the results of the analyses, a new parameter, equivalent Gaussian spread (EGS), is introduced. The parameter EGS specifies the range in terms of equal positive and negative logarithmic units from the mean that would encompass errors with the same apriori probability as would a Gaussian distribution with a standard deviation equal to EGS; in other words, the range from -1 EGS to +1 EGS contains about two-thirds of the errors. For Gaussian distributions of logarithmic errors, EGS and standard error are equivalent. EGS is reported herein in units of percentage and an approximate interpretation of EGS is, "Two-thirds of the errors in instantaneous streamflow data will be within plus or minus EGS percent of the reported value."

\section{The Application of K-CERA in lowa}

A rating analysis to define the time series of residuals was performed on 100 of the 110 continuous streamflow stations in lowa. Discharge measurements were considered for the past 10 years. The residuals of measured discharges from the long-term rating were analyzed by time series technique to determine the input parameters of the Kalman-filter streamflow records. The error variance, Vf, was computed as a function of the time-series parameters, the discharge-measurementerror variance and the frequency of discharge measurement. The rating function for all stations was of the form:

$$
\mathrm{LQM}=\mathrm{B1}+\mathrm{B} 3 * \operatorname{LOG}(\mathrm{GHT}-\mathrm{B} 2)
$$

where

LQM is the logarithm (base e) of the measured discharge;

GHT is the record gage height of the measurement, in feet;

B1 is the logarithm of discharge for a flow depth of 1 foot;

B2 is the gage height of zero flow, in feet; and

B3 is the slope of the rating curve.

The various functions for each station are listed in table 6 . The rating analysis was based on open-water conditions only. Backwater from ice can be expected on an average of 3 months per year and seriously affects the stagedischarge relation. In general, stage-discharge ratings for the lowa stations are subjected to shifting control, especially in the low-water range because of scour and fill of alluvial material.

From the residuals of the rating analysis, the 1-day auto-correlation coefficient, process variance, and discharge-measurement variance were computed. Four other stations had been analyzed in a previous study (Kitanidis and others, 1984) of the Missouri River ratings. These data were added to the study at this point. Six stations were not included in this study and were processed as stations with zero weight in the traveling hydrographer program. They were the following: (1) Mississippi River at McGregor (05389500), Mississippi River at Clinton (05420500), and Mississippi River at Keokuk $(05474500)$ that require slope ratings and were not analyzed by Kalman-filtering techniques; and (2) Crow Creek at Bettendorf (05422470), Middle Raccoon River near Newell (05482135) and Perry Creek at Sioux City (06600000) that had too short a period of record for a rating analysis. 
The coefficient of variation ( $\mathrm{CV}$ ) of daily discharges and the cross correlation coeficient ( $P C$ ) between nearby stations were computed for all stations being analyzed. Daily streamflow records for each of the 104 stations for the past 30 years of record were retrieved from WATSTORE (Hutchison, 1975). The value $\mathrm{CV}$ was computed for each of the stations having 3 or more years of data. One or more stations were designated for cross correlation for each station and Pc computed. The coefficients for each station and the corresponding correlative stations are listed in table 6.

An estimate of lost record, in percent, was determined by examining 10 years of record at 10 representative stations that were visited monthly. During this period, gage-height data was totally missing 3 percent of the time. Most gaging stations in lowa have back-up equipment so the failure of one recorder does not necessarily lose record for the station. Also, 69 percent of the stations are telemetered with telemark, binary-decimal transmitter (BDT), Device for Automatic Remote Data Collection (DARDC), remote, radio or data-collection platform (DCP) systems. All of these stations are monitored from the offices at least weekly. If the station is not working, someone in the area checks it out. Plans are in progress to provide telemetry at approximately 85 percent of the stations withing the next 2 years. More reliable timers, batteries and motors installed this year justifies using the 3 -percent lost record estimate for future operation.

The uncertainty functions for each of the 104 stations were then computed using the above parameters. The residuals about rating curves for many stations in lowa do not follow a first-order Markov process. Significant changes in ratings resulting from channel changes, usually resulting from periodic floods occur at these stations. These may shift with each flood, but will not necessarily return to the original rating after a change. In addition, several stations apparently have discontinuous ratings that change as the flow regime changes. These regime changes can occur as a result of changes in stage, water temperature, or suspended-sediment load. A total of 31 of the 104 stations analyzed were determined to not follow the assumptions of the model and were excluded from the calculation of standard error of estimate in the travelling hydrographer program by assigning zero weight to the station's uncertainty function. Those stations are so indicated in table 6.

The K-CERA application pertained only to a 280-day period of open water. A separate cost estimate was determined for winter operation and included in the fixed cost of the station. In lowa, the winter record is based on a combination of several factors. First, the daily discharge is computed as in the open-water period. These values are plotted by computer on a hydrograph with respect to day. Actual discharge measurements are made during the ice-effected period and the data plotted on the hydrograph. The data are always less than that computed by the open-water rating if there is backwater from ice. The maximum and minimum daily temperatures for the regional area of the station and the abnormal fluctuations of stages are used as indicators of the presence of ice effect. Extra visual observations by hydrographers, precipitation records, and observer reports verify the ice condition. Two or more nearby stations are examined together to add information to the entire evaluation of the magnitude of ice effect. For example, one station may be measured in the first week of a month, whereas others may be measured in the second or third week. On the basis of the above information for all of the stations assumed to be similarily affected, the open-water discharge is adjusted to a realistic actual discharge. The ratio of the actual discharge to the computed open-water discharge is used to adjust the intervening days between measurements. By using a hydrographic plot in logarithmic units, this ratio is the linear distance between the measured 
and computed values. This distance can be varied between measurement dates or control points by considering the trend in temperatures and abnormal gage-height flucuations.

Winter records with severe backwater from ice at stations in lowa are rated poor (>15 percent). The magnitude of ice effect may vary during the day. An actual discharge measurement every day would improve the accuracy of the record but the data may still be in considerable error. The ice effect usually is more consistent if the stream surface freezes completely at the beginning of winter and remains frozen until spring. A discharge measurement made soon after the freeze, one during the middle of winter and one just before melting, can give a fairly good trend for the whole period. However, this situation seldom happens as temperatures fluctuate enough to cause cyclic periods of ice cover and open water. For this study, three ice measurements per year were budgeted at twice the open-water unit and route costs and entered in the fixed cost of the station.

Visit costs are those associated with paying the hydrographer for the time actually spent at a station servicing the equipment and making a discharge measurement. These costs vary from station to station and are a function of the difficulty and time required to make the discharge-measurement Average visit times were calculated for each station based on an analysis of dischargemeasurement data available. This time was then multiplied by the average hourly salary of hydrographers in the lowa offices to determine total visit costs. Route costs include the vehicle cost associated with driving the number of miles it takes to cover the route, the cost of the hydrographer's time while in transit, and any per diem associated with the time it takes to complete the trip.

\section{K-CERA Results}

The "Traveling Hydrographer Program" uses the uncertainty functions along with the appropriate cost data and route definitions to compute the most costeffective way of operating the stream-gaging program. In this application, the first step was to simulate the current practice and determine the total uncertainty associated with it. To accomplish this, the number of visits being made to each stream gage and the specific routes that are being used to make these visits were fixed. In lowa, current practice indicates that discharge measurements are made 90 percent of the time that a station is visited. The resulting average error of estimation for the current practice in lowa is plotted as a point in figure 9 and is 11.4 percent.

The upper line in figure 9 represents the minimum level of average uncertainty that can be obtained for a given budget with 3 percent lost record and the existing instrumentation and technology. The line was defined by compiling results of several runs of the traveling hydrographer program with different budgets for each of the three offices. Constraints on the operations other than budget were defined as described below. The lower line defines the average uncertainty versus budget considering no lost record.

Except for the 3 index stations, 5 Missouri and 3 Mississippi River stations, streamflow stations are currently visited every 6 weeks in lowa. Consideration is given to the physical limitations of the equipment at the gage, such as battery duration, capacity of the tape spools of the recorder, purging of the orifice line or intakes, nitrogen-gas supply, and freezing problems. The effect of visitation frequency on the accuracy of the data and the quantity of lost record is taken into account in the uncertainty analysis. In lowa, a minimum requirement of 5 visits during the open water season (280 days) was designated; for the winter season, the minimum was 3 visits. 


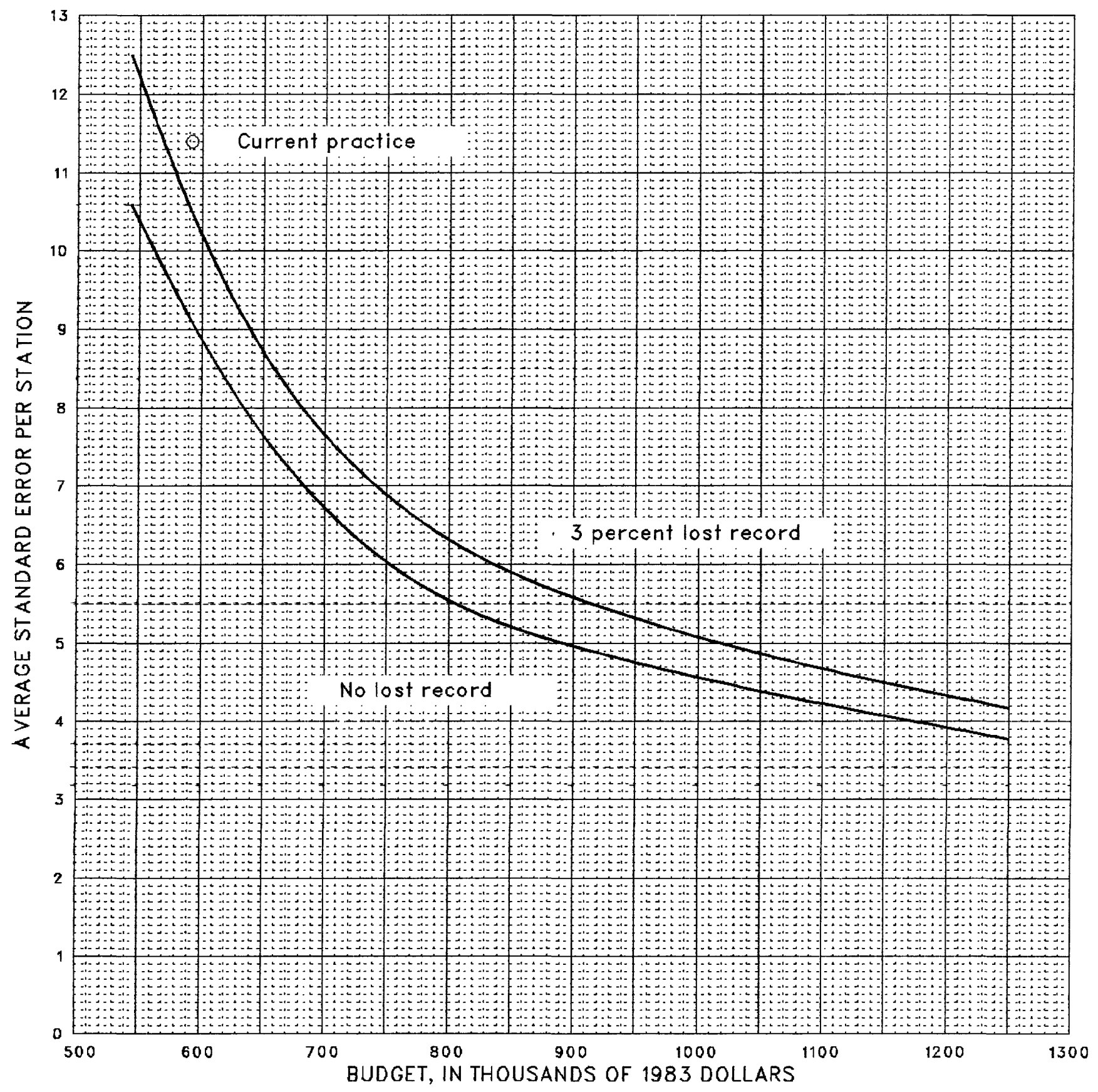

Figure 9.--Temporal average standard error per gage. 


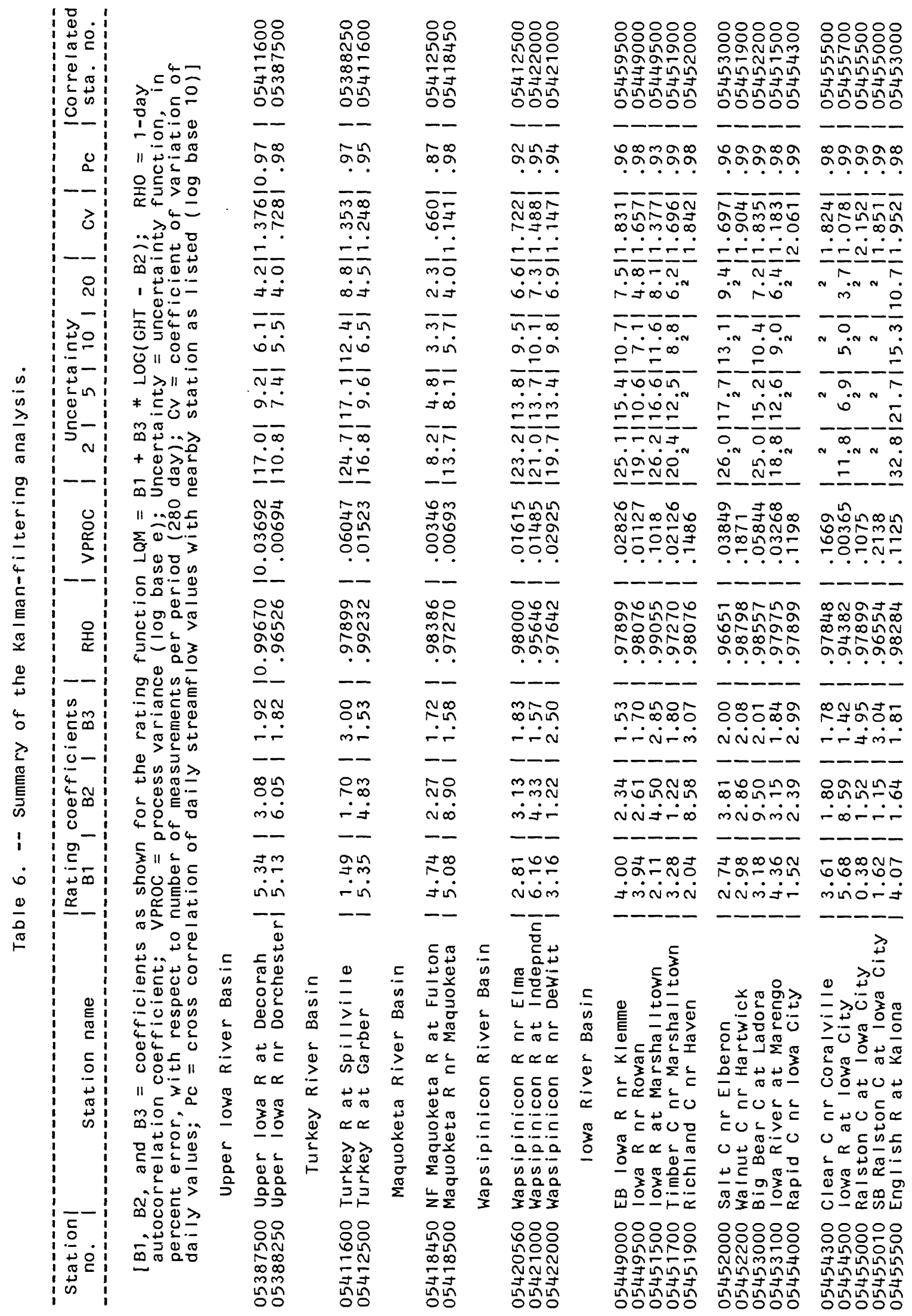




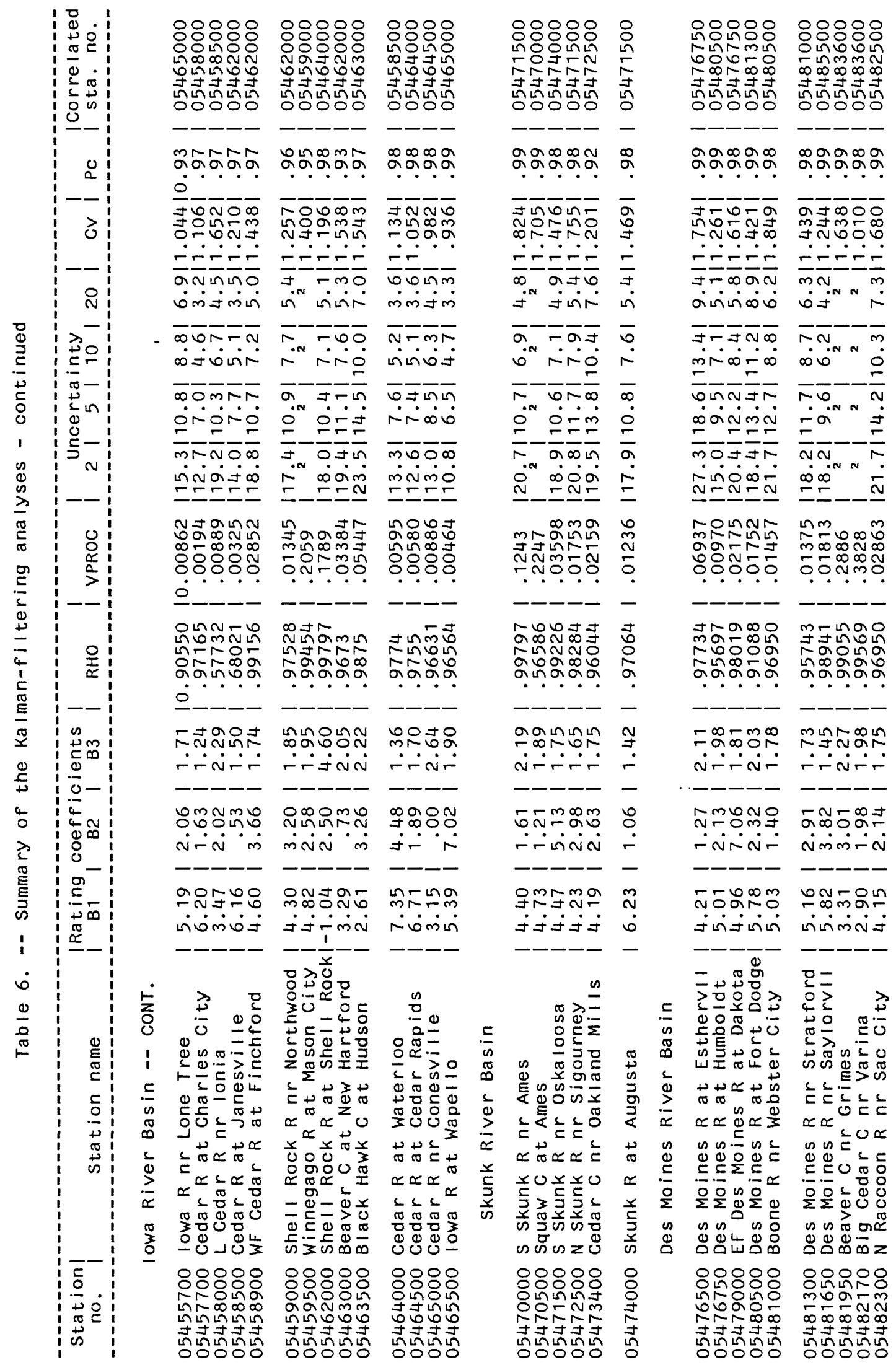




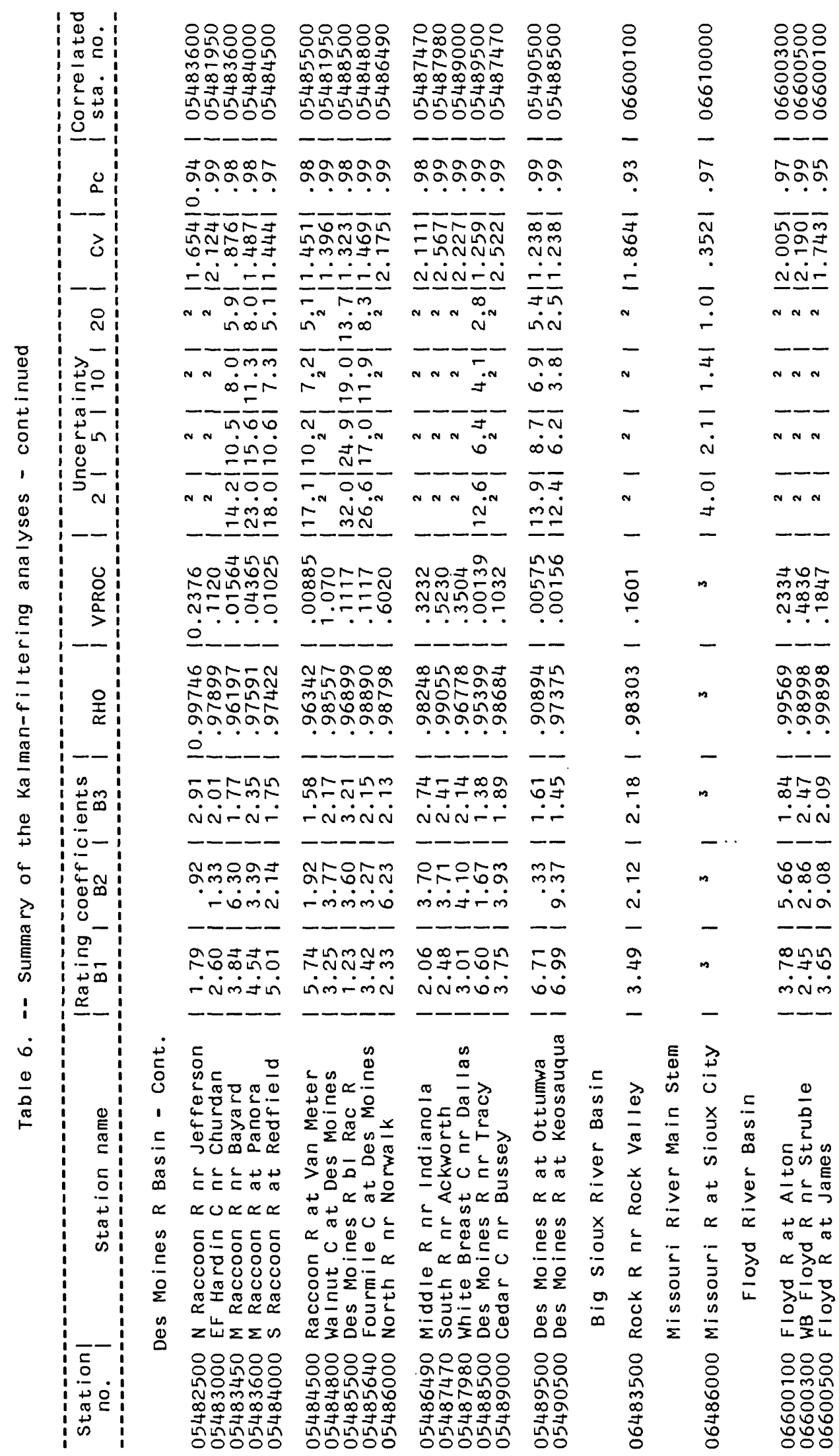




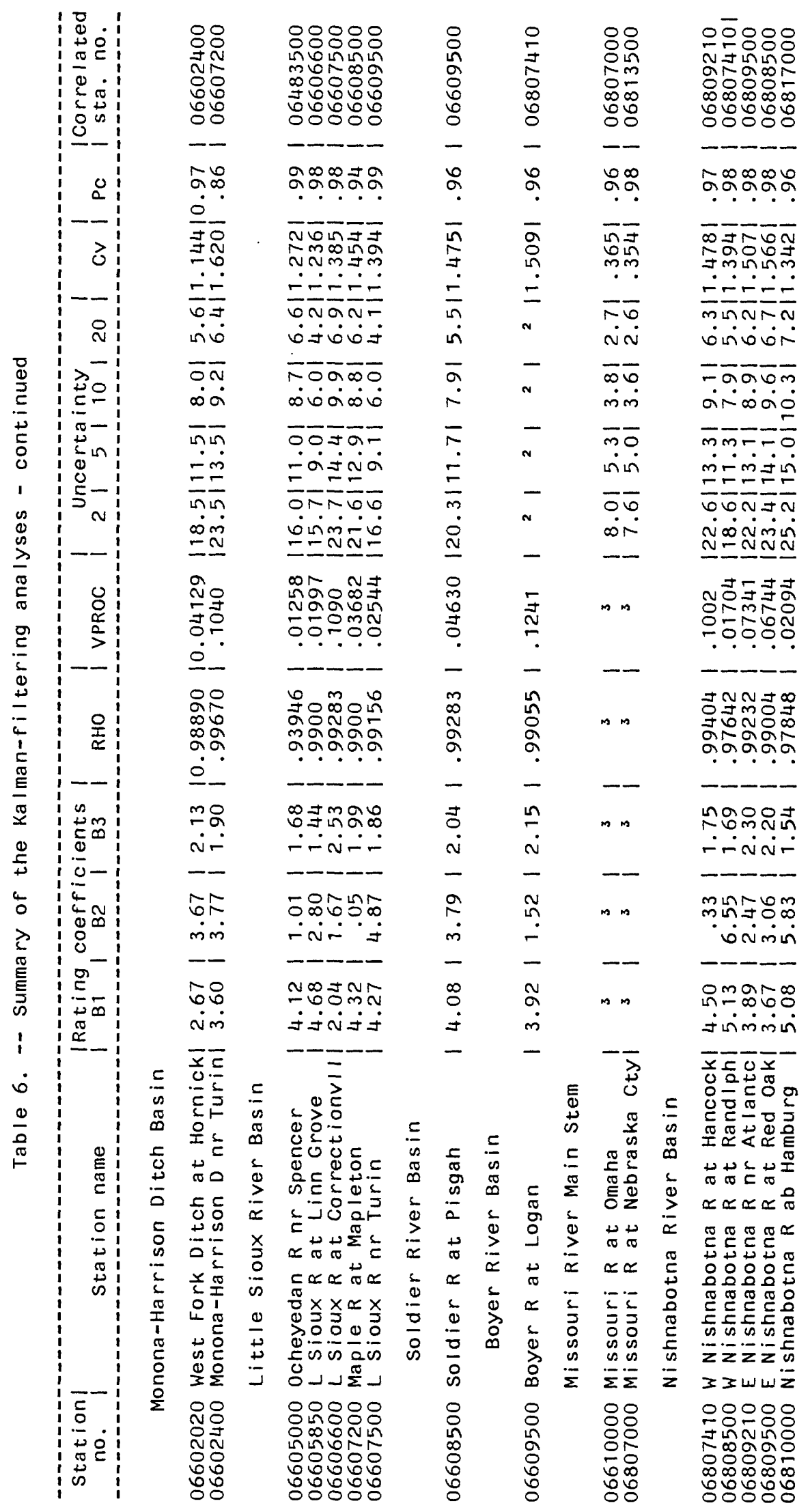




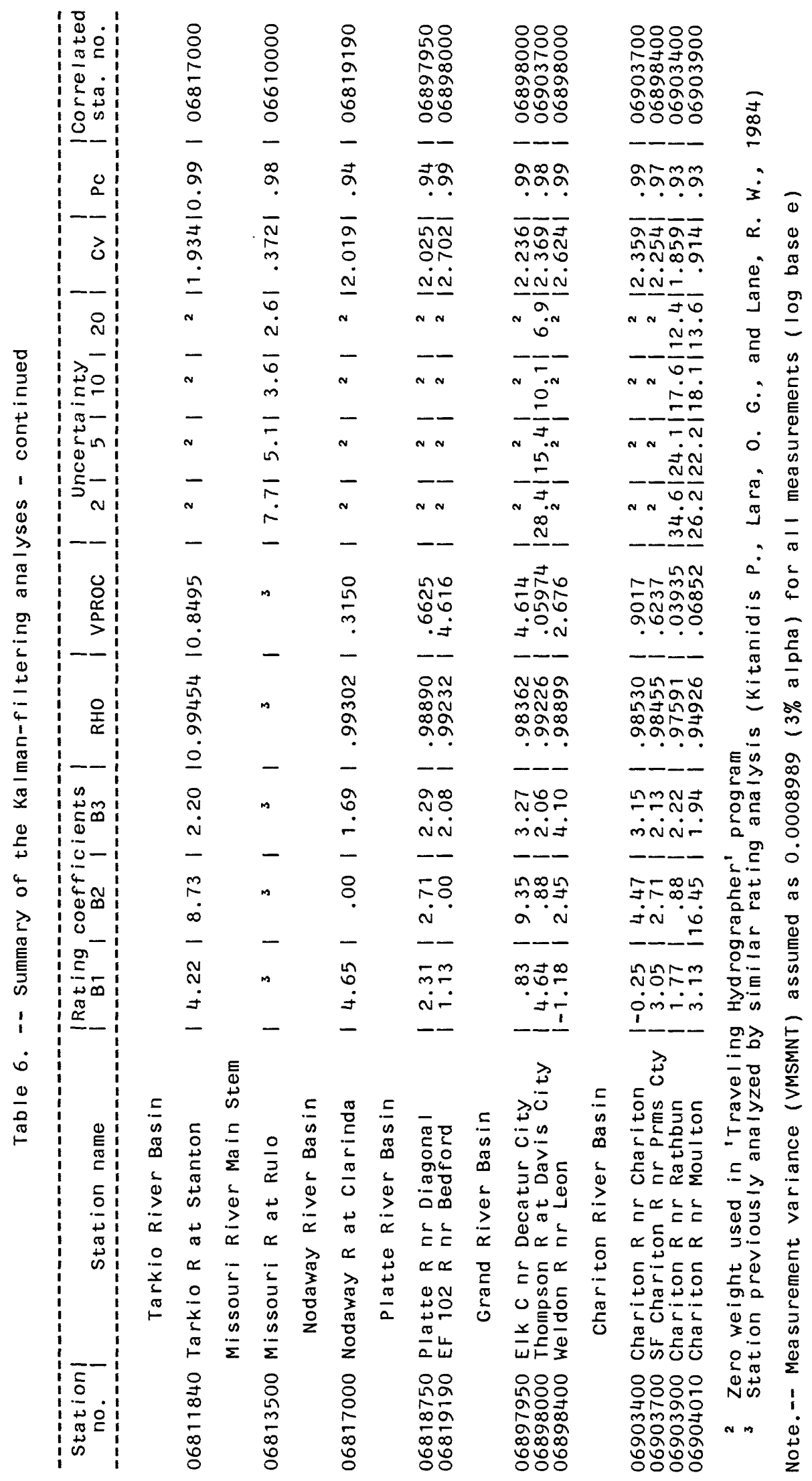


Minimum-visit requirements also control the need to visit stations for special reasons such as water-quality and sediment sampling. In lowa, all water-quality work is integrated with the surface-water fieldwork and, therefore, does affect minimum-visit requirements.

Operation of the Missouri River reservoir system by the U. S. Army Corps of Engineers requires intensive scheduling of discharge measurements. Measurements are needed twice $a$ week at Sioux City (06486000), Omaha (06610000), and Nebraska City (06807000), and once a week at Decatur (06601200), and Rulo (06813500) during the navigation season: Studies of stagedischarge ratings using K-CERA techniques (Kitanidis and others, 1984), are discussed in the next section and indicate that the frequency of measurements could be decreased by correlating water temperature with the stage-discharge relationship and applying the daily K-CERA computer analysis.

Visitations at the three index stations are monthly for the purpose of pulling the gage-height record and processing it for the monthly report of hydrologic conditions. A DCP was installed recently at one station and will soon be installed at the remaining two. This equipment will allow the record to be processed without visiting the stations monthly and also will provide a daily check on proper operation. See table 7 for a summary of the routes that were analyzed to visit the stations with minimum-visit constraints and cost-effective scheduling.

The results in figure 9 and table 8 summarize the K-CERA analysis and are predicated on a discharge measurement being made 90 percent of the times that a station is visited. Ideally, the ratio of measurements to visits would be optimized for each site individually. This step will be accomplished in a future evaluation of the lowa program.

An analysis also was performed assuming no lost record. The quantity of lost record affects the accuracy of the data as shown in figure 9 . The uncertainty functions also were computed for each station for 6 percent lost record. A separate analysis for the travelling hydrographer program was not made for this condition but the standard error of the uncertainty function, on the average, increased approximately 65 percent as the lost record increased from 3 to 6 percent. Lost record can be decreased significantly by the use of quality instrumentation, proper maintenance, and well-trained hydrographers. Telemetry of the gages permits checking the operation status from the office at any time frequency desired. A regularly scheduled interrogation of gages will provide the basis to revisit the gaging site to decrease the lost record.

\section{An application of K-CERA to stations on the Missouri River}

So far the stream-gaging options discussed in this report usually specify $N$ number of visits per year spaced at approximately regular intervals throughout the year. This approach is acceptable as long as the stability of the stagedischarge relations in the network is comparable. However, including alluvial streams in the network may create problems because stage-discharge relations in alluvial streams change continually, and usually markedly, in a short time.

The lowa District has four gaging stations on the Missouri River that are in this category. For this reason, concurrently with this study, the District conducted a project with the objective of developing a method to evaluate the efficiency of streamflow-data collection strategies for alluvial rivers. 
Table 7.--Summary of rot as used to visit stations in lowa.

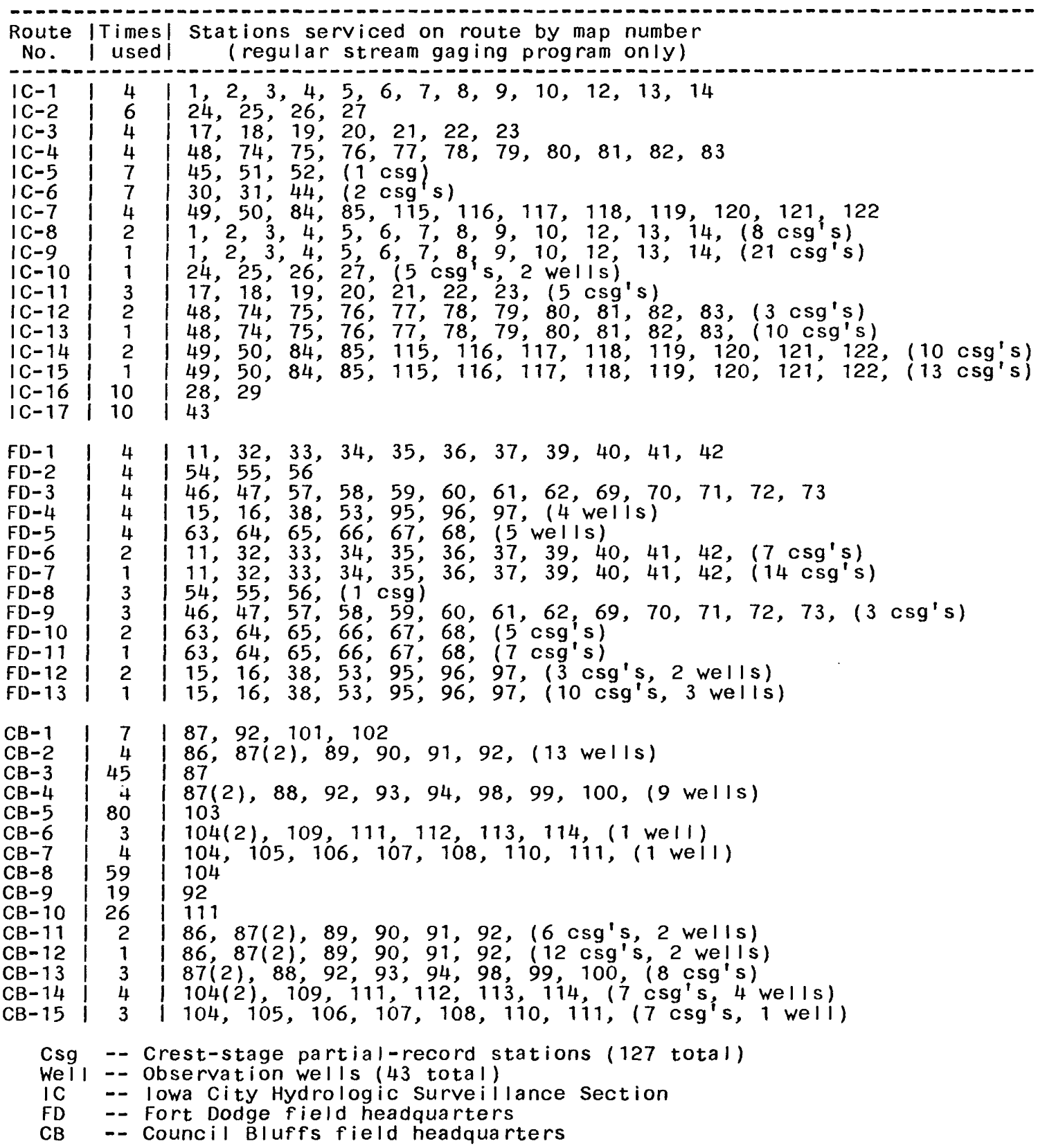




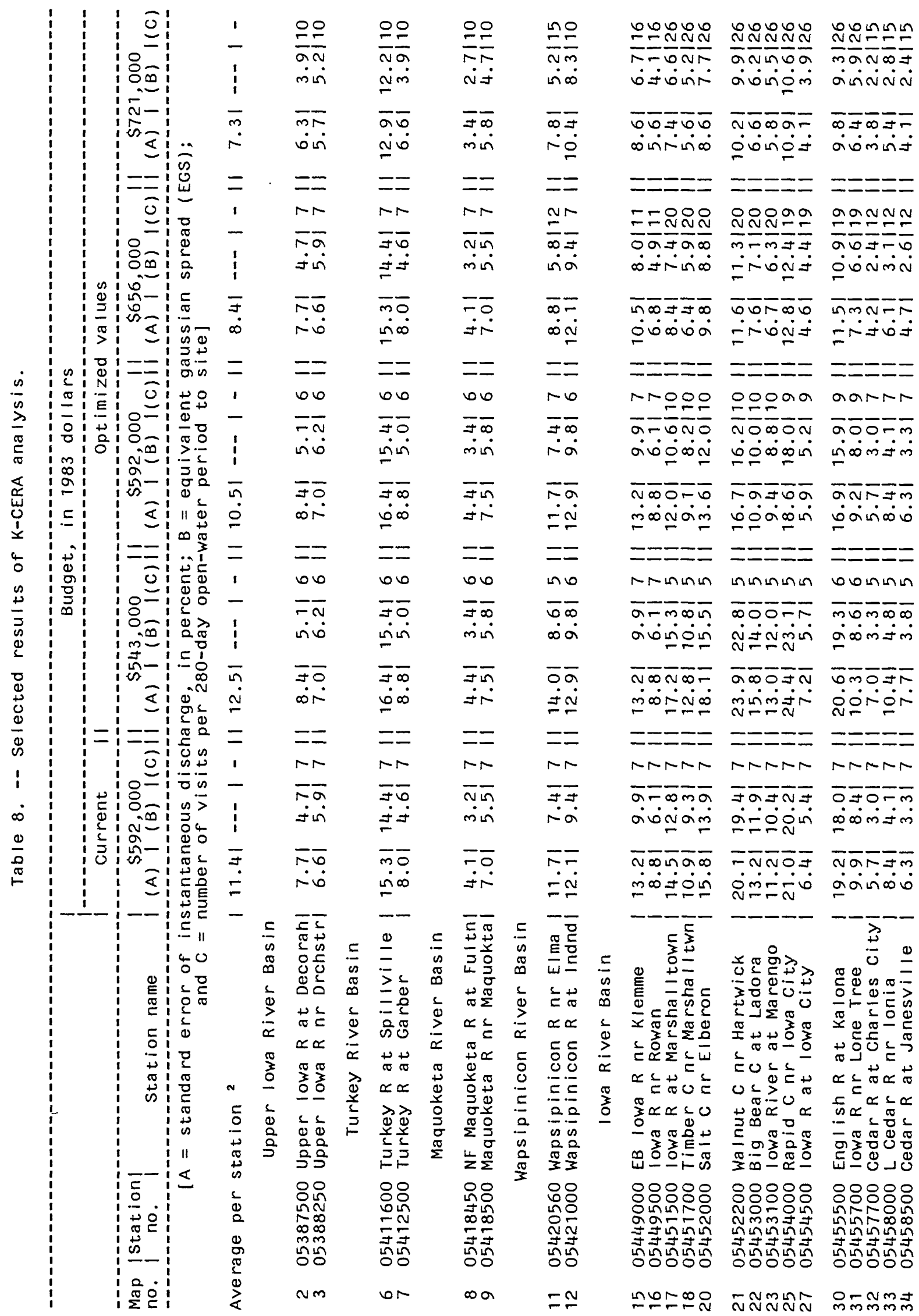




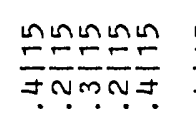

于rinimi

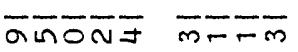

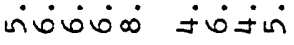

ニニニニニ ニニニニ

NN NaR

프은

जिiांकिष

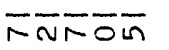

orioria

二ニ二二

nRrNa

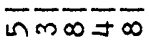

טirjo

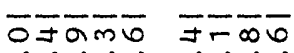

वंबioñin

二=ニ二

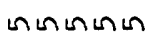

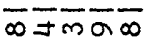

rioji

二二二

UInOL

OF⿻

푸요

$-\cdots=$

$-=-$

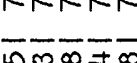

טirijo

ज्ञ̄ज बiaioin

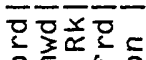

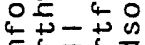

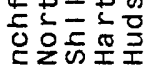

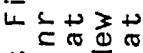

तथ⿻

$\simeq x x+4$

요워

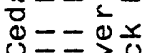

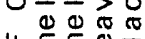

岇的舟品

용ㅇㅇㅇ

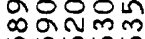

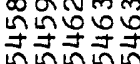

戸戸すす

nivin

$\bar{\infty}=\overline{-\sigma}$

$\sim \infty \infty^{\circ}$

$=-$

ron

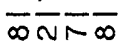

चنंi்

जण

نंinin

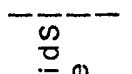

:으은

도응

00

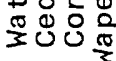

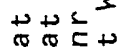

$\llbracket \propto ⿻ \pi$

156

중 $\frac{\pi}{0} \frac{\pi}{0}$

웡요

용요용

武结

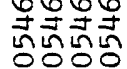

잉잉ㅇㅇ

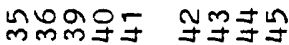

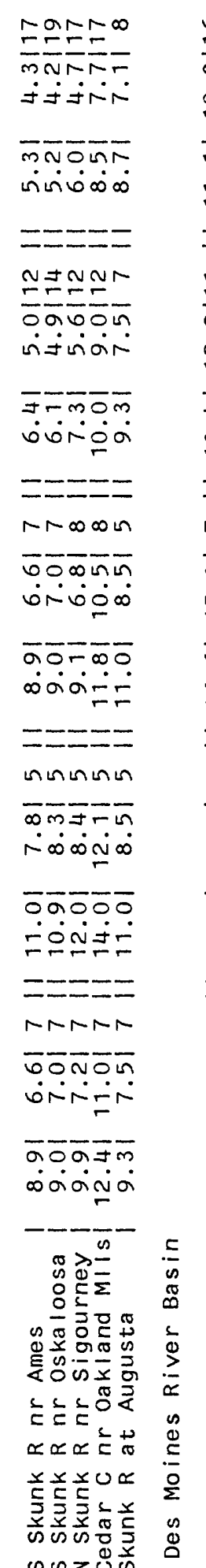

늠을ำ

변in

ニำニ

ஸिं0ं0

テテテ̄̄a

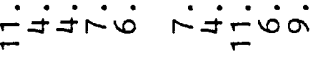

NNNOA नू

ニニニニニ ニニニニニ

-NRNN NNRNN

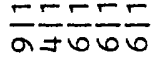

जinivioi

政

অळঢ̄

minivoio

二ニニニ

$r=5=r$

$\frac{5}{\infty}=\frac{5}{\infty}$

ํํํ요

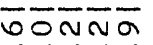

수웅

Z二=-

Magain

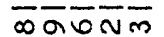

nír-i

जिन-

ora-i

- $=-$

MNNR

চ何的的

수 $\dot{\infty}=\dot{0}$

ODLño

बinisim

ठवज可

லீNㅇㅁ

चक्षित

orian

二풍

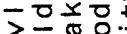

음워

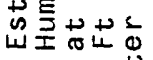

तथ

$\simeq \propto \stackrel{\infty}{0} \propto \frac{0}{3}$

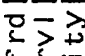

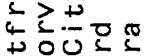

क्षे

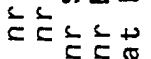

$\simeq \propto \propto ⿻ 上 丨$

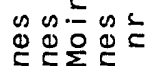

凹四

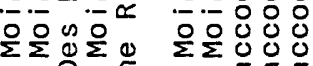

$\sum \sum 巳 \sum$

为西品

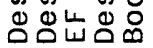

品 $z \Sigma \Sigma$

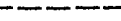

Nニコ Nㅡ

Nত্রিল =

viñón

$\cos \geq 0$

응용ㅇㅇㅇㅇㅇㅇㅇ

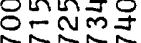

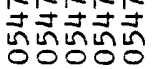

윤용ㅇㅇㅇㅛ

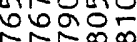

앙요용용

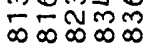

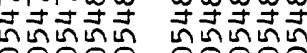

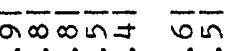
ம்ं-் $\dot{0}$

二-二= $=$

nNar $\infty \infty$

ज亦市

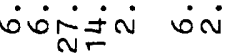

का airivi N-

二ニ二ニ二 二二

uninginin unin

इ000ত $=\overline{0}$

솦ㅇ ñ

$\infty \bar{m} \bar{\infty} \bar{\infty}$ 00giti

ठ이잉

웎옵ํำ

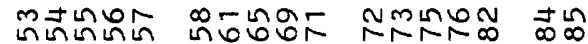

andra na

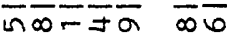

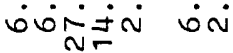

oxmor āa

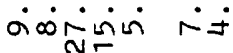

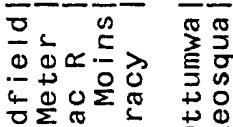

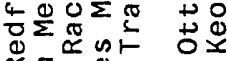

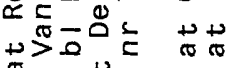

๙

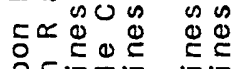

엉으을

๔0心

응유용 윤유

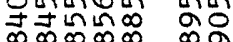

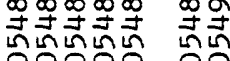







Kalman-filtering techniques were used to develop a flexible and expedient model describing the variability of discharges and shifts of the stage-discharge relations of alluvial rivers. An explanation of the method, a description of the model, and its applications have been described by Kitanidis and others (1984). Briefly, they found that the error in the stage-discharge relation was a function of water temperature. The stage-discharge relationship changes as the streambed form changes. The bed form relates to the ability of the water to suspend the sediment which is related to the water temperature. During winter, the bed form is smooth and during summer, the bed form has large, moving dunes. Therefore, for a given stage, the discharge is greater during the winter when the stream bed is smooth. The K-CERA analysis predicts the next day's discharge and the standard error. When the error exceeds the accuracy required, a discharge measurement is scheduled to adjust the next day's analysis. This is a good example of the need and importance of good record and accurate data for project operations.

The model mentioned above was used in simulations designed to evaluate a number of various sampling strategies. From these simulations it was concluded that the optimal approach would be to adopt a "real-time" stream-gaging strategy that will allow the District to maximize quality of data with a given budget. To accomplish this approach the following steps need to be taken:

1. Install telemetering equipment with automatic data-transfer capability in each of the gaging stations. Telemetering equipment has been installed.

2. Provide the Council Bluffs field headquarters with a microcomputer to access the model and the site-specific model parameters on line, and with the capability of interphasing with the telemetering equipment.

3. Develop computer programs that will enable the microcomputer to query each of the stations for pertinent data at 6-hour intervals and store them in memory.

4. Develop computer programs that will operate the model at the end of each day. The estimated discharge and its corresponding standard error of estimate for each station will be printed daily.

Based on the magnitude of current estimation error, the hydrologist in charge would decide if a measurement at a particular station on the river is needed that day or soon after.

\section{Summary of the Third Phase of Analysis}

Results of the K-CERA analysis are:

1. Visits to gaging stations need to be maintained at 7 per open-water period (280 days) and 3 per. winter period. By optimizing the gaging schedule, the average standard error would be decreased from 11.4 to 10.5 percent with the same budget of $\$ 592,000$.

2. The amount of funding for stations with accuracies that are not acceptable for the data uses need to be renegotiated with the data users.

3. The K-CERA analysis needs to be made whenever new stations are added and sufficient information about the characteristics of the new stations has been obtained. 
4. Techniques for decreasing the probabilities of missing record, for example increased use of satellite relay of data and updated equipment need to be explored and evaluated as to their cost-effectiveness in providing streamflow information.

5. The "traveling hydrographer" analysis needs to be made each year or whenever new field schedules are needed to optimize field operation.

6. Data collection of other hydrologic parameters needs to continue in the streamflow data program. The K-CERA analysis shows a significant savings in travel time and route cost for the present programs of creststage stations and observation wells.

7. The lowa District needs to take the necessary steps to implement the "real-time" stream-gaging strategy for the stations on the Missouri River. Implementing this strategy would be beneficial not only to lowa but nationwide. The Geological Survey needs to demonstrate to cooperators and administrators that our agency is determined to optimize the operation of our networks, and has the capability of using the tools currently available.

\section{SUMMARY}

Currently (1983), there are 110 continuous streamflow stations, being operated in lowa at a cost of $\$ 592,000$. Additional stations in the regular surface water program include 4 reservoir, 4 lake, 3 stage only and 1 miscellaneous station that are budgeted separately. Seventeen separate sources of funding contribute to the continuous streamflow program and six separate uses were identified. The data use for all of the stations are necessary as defined. Twelve of the 51 stations classified as "regional hydrology" are not funded for other uses. These stations would be the only candidates for discontinuance when sufficient definition of transferable hydrologic data is obtained. Emphasis needs to be placed on expanding the streamflow-data-collection program to include the 21 ungaged streams with drainage areas between 200 and $400 \mathrm{mi}^{2}$.

No daily discharges can be estimated accurately enough by using regressioncorrelation or flow-routing techniques. One study in the Skunk River basin indicates a need for a station downstream from the water-treatment plant at Ames if more accurate streamflow data are needed for plant operation. Knowledge from the flow-routing studies will improve estimation or reconstruction of lost record at a station in the set of routing stations. Although the results of the alternative method study for station 42 (Cedar River at Waterloo) and station 56 (Des Moines River at Fort Dodge) are encouraging if the models are calibrated to their full potential, the data use for these stations require a greater degree of accuraccy than that possible from the present models.

It was shown that the current operating budget for 110 streamflow sites required a budget of $\$ 592,000$. The temporal average standard error would be improved from 11.4 percent for current practice to 10.5 percent if the gaging schedule was optimized. The average standard error would be improved to 8.4 percent with a 10 percent increase to the present budget to $\$ 656,000$ and to 4.2 percent with a budget of $\$ 1,235,000$.

A major component of the error in streamflow records is caused by loss of gage-height record because of malfunctions of sensing and recording equipment. Upgrading of equipment, adding telemetry, and frequent monitoring of instrument operation would decrease the loss of record. 
Cost-effective studies of the stream-gaging program need to be continued. Future studies also will be required because of changes in demands for streamflow information. The optimum ratio of discharge measurements, site visits, and accuracy of data need to be determined. 


\section{REFERENCES CITED}

Benson, M. A., and Carter, R. W., 1973, A national study of the streamflow data-collection program: U.S. Geological Survey Water-Supply Paper 2028, $44 \mathrm{p}$.

Bowie, J. E., and Petri, L. R., 1969, Travel of solutes in the lower Missouri River: U. S. Geological Survey Hydrologic-Invest-igations Atlas HA-332.

Burmeister, I. L., 1970, The streamflow data program in lowa: U. S. Geological Survey open-file report, $82 \mathrm{p}$.

Draper, N. R., and Smith, H., 1966, Applied regression analysis (2d ed.): New York, John Wiley, $709 \mathrm{p}$.

Fontaine, R. A., Moss, R. E., Smath, J. A., and Thomas, W. O., 1983, Cost effectiveness of the stream-gaging program in Maine: $U$. S. Geological Survey Survey Open-File Report, $81 \mathrm{p}$.

Gelb, A., ed., 1974, Applied optimal estimation: Cambridge, Mass., The Massachusetts Institute of Technology Press, $374 \mathrm{p}$.

Gilroy, E. J., and Moss, M. E., 1981, Cost-effective stream-gaging strategies for the Lower Colorado River Basin: U.S. Geological Survey Open-File Report 81-1019, _. p.

Hutchison, N. E., 1975, WATSTORE User's guide, volume 1: U.S. Geological Survey Open-File Report 75-426, __p.

Keefer, T. N., 1974, Desktop computer flow routing: American Society of Civil Engineers Proceedings, Journal of the Hydraulics Division, $v .100$, no. HY7, p. 1047-1058.

Keefer, T. N., and McQuivey, R. S., 1974, Multiple linearization flow routing model: American Society of Civil Engineers Proceedings, Journal of the Hydraulics Division, v. 100, no. HY7, p. 1031-1046.

Kitanidis, P., Lara, O. G., and Lane, R. W., 1984, Evaluation of the efficiency of streamflow data-collection strategies for alluvial rivers: U. S. Geological Survey Water-Supply Paper [in press].

Kleinbaum, D. G., and Kupper, L. L., 1978, Applied regression analysis and other multivariable methods: North Scituate, Mass., Duxbury Press, 556 p.

Lara, O. G., 1973, Floods in lowa: Technical manual for estimating their magnitude and frequency: lowa Natural Resources Council Bulletin No. 11, $56 \mathrm{p}$.

1979, Annual and seasonal low-flow characteristics of lowa streams: U. S. Geological Survey Open-File Report 79-555, 507 p. 
Larimer, O. J., 1957, Drainage areas of lowa streams: lowa Highway Research Board Bulletin No. 7, 437 p. (reprinted 1974).

Mitchell, W. D., 1972, Effect of reservoir storage on peak flow: U.S. Geological Survey Water-Supply Paper 1580, p. C1-C25.

Moss, M. E., and Gilroy, E. J., 1980, Cost-effective stream-gaging strategies for the Lower Colorado River Basin: U.S. Geological Survey Open-File Report 80-1048, $111 \mathrm{p}$.

Riggs, H. C., 1973, Regional analysis of streamflow characteristics: U.S. Geological Survey Techniques of Water-Resources Investigations, Book 4, Chapter B3, $15 \mathrm{p}$.

Sauer, V. B., 1973, Unit response method of open-channel flow routing: American Society of Civil Engineers Proceedings: Journal of the Hydraulics Division, v. 99, no. HY1, p. 179-193.

Thomas, D. M., and Benson, M. A., 1970, Generalization of streamflow chacteristics from drainage-basin characteristics: U.S. Geological Survey Water-Supply Paper 1975, 55 p.

U.S. Geological Survey, 1983, Water-Resources data for lowa, water year 1982: U.S. Geological Survey Water-Data Report IA-82-1, 262 p. 


\section{Description of Uncertainty Functions}

As noted earlier, uncertainty in streamflow records is measured in this study as the average relative variance of estimation of instantaneous discharges. The accuracy of a streamflow estimate depends on how that estimate was obtained. Three situations are considered in this study: (1) streamflow is estimated from measured discharge and correlative data using a stagedischarge relation (rating curve), (2) the streamflow record is reconstructed using secondary data at nearby stations because primary correlative data are missing, and (3) primary and secondary data are unavailable for estimating streamflow. The variances of the errors of the estimates of flow that would be employed in each situation were weighted by the fraction of time each situation is expected to occur. Thus the average relative variance would be

$$
\nabla=\varepsilon_{f} V_{f}+\varepsilon_{r} V_{r}+\varepsilon_{e} V_{e}
$$

with

$$
1=\varepsilon_{f}+\varepsilon_{r}+\varepsilon_{e}
$$

where

$\bar{\nabla}$ is the average relative variance of the errors of streamflow estimates,

$\varepsilon_{f}$ is the fraction of time that the primary recorders are functioning,

$V_{f}$ is the relative variance of the errors of flow estimates from primary recorders,

$\varepsilon_{r}$ is the fraction of time that secondary data are available to reconstruct streamflow records given that the primary data are missing,

$V_{r}$ is the relative variance of the errors of estimation of flows reconstructed from secondary data,

$\varepsilon_{e}$ is the fraction of time that primary and secondary data are not available to compute streamflow records, and

$V_{e}$ is the relative error variance of the third situation. 
The fractions of time that each source of error is relevant are functions of the frequencies at which the recording equipment is serviced.

The time $\tau$ since the last service visit until failure of the recorder or recorders at the primary site is assumed to have a negative-exponential probability distribution truncated at the next service time; the distribution's probability density function is

$$
f(\tau)=k e^{-k \tau} /\left(1-e^{-k s}\right)
$$

where

$k$ is the failure rate in units of (day $)^{-1}$,

$e$ is the base of natural logarithms, and

$s$ is the interval between visits to the site in days.

It is assumed that, if a recorder fails, it continues to malfunction until the next service visit. As a result,

$$
\varepsilon_{f}=\left(1-e^{-k s}\right) /(k s)
$$

(Fontaine and others, 1983, eq. 21).

The fraction of time $\varepsilon_{e}$ that no records exist at either the primary or secondary sites can also be derived assuming that the time between failures at both sites are independent and have negative exponential distributions with the same rate constant. It then follows that

$$
\varepsilon_{e}=1-\left[2\left(1-e^{-k s}\right)+0.5\left(1-e^{-2 k s}\right)\right] /(k s)
$$

(Fontaine and others, 1983, eqs. 23 and 25).

Finally, the fraction of time $\varepsilon_{r}$ that records are reconstructed based on data from a secondary site is determined by the equation

$$
\begin{aligned}
\varepsilon_{r} & =1-\varepsilon_{f}-\varepsilon_{e} . \\
& =\left[\left(1-e^{-k s}\right)+0.5\left(1-e^{-2 k s}\right)\right] /(k s)
\end{aligned}
$$


The relative variance, $V_{f}$, of the error derived from primary record computation is determined by analyzing a time series of residuals that are the differences between the logarithms of measured discharge and the rating curve discharge. The rating curve discharge is determined from a relationship between discharge and some correlative data, such as water-surface elevation at the gaging station. The measured discharge is the discharge determined by field observations of depths, widths, and velocities. Let $\mathrm{qT}_{\mathrm{T}}(t)$ be the true instantaneous discharge at time $t$ and let $q_{R}(t)$ be the value that would be estimated using the rating curve. Then

$$
x(t)=\ln q_{T}(t)-\ln q_{R}(t)=\ln \left[q_{T}(t) / q_{R}(t)\right]
$$

is the instantaneous difference between the logarithms of the true discharge and the rating curve discharge.

In computing estimates of streamflow, the rating curve may be continually adjusted on the basis of periodic measurements of discharge. This adjustment process results in an estimate, $q_{c}(t)$, that is a better estimate of the stream's discharge at time $t$. The difference between the variable $\hat{x}(t)$, which is defined

$$
\hat{x}(t)=\ln q_{c}(t)-\ln q_{R}(t)
$$

and $x(t)$ is the error in the streamflow record at time $t$. The variance of this difference over time is the desired estimate of $V_{f}$. Unfortunately, the true instantaneous discharge, $q_{T}(t)$, cannot be determined and thus $x(t)$ and the difference, $x(t)-\hat{x}(t)$, cannot be determined as we11. However, the statistical properties of $x(t)-\hat{x}(t)$, particularly its variance, can be inferred from the available discharge measurements. Let the observed residuals of measured discharge from the rating curve be $z(t)$ so that 


$$
z(t)=x(t)+v(t)=\ln q_{m}(t)-\ln q_{R}(t)
$$

where

$v(t)$ is the measurement error, and

in $q_{m}(t)$ is the logarithm of the measured discharge equal to ${ }^{n} q_{T}(t)$ plus $v(t)$.

In the Kalman-filter analysis, the $z(t)$ time series was analyzed to determine three site-specific parameters. The Kalman filter used in this study assumes that the time residuals $x(t)$ arise from a continuous firstorder Markovian process that has a Gaussian (normal) probability distribution with zero mean and variance (subsequently referred to as process variance) equal to p. A second important parameter is $B$, the reciprocal of the correlation time of the Markovian process giving rise to $x(t)$; the correlation between $x\left(t_{1}\right)$ and $x\left(t_{2}\right)$ is $\exp \left[-\beta\left|t_{1}-t_{2}\right|\right]$. Fontaine and others (1983) also define $q$, the constant value of the spectral density function of the white noise which drives the Gauss-Markov x-process. The parameters, $p, q$, and $B$ are related by

$$
\operatorname{Var}[x(t)]=p=q /(2 B)
$$

The variance of the observed residuals $z(t)$ is

$$
\operatorname{Var}[z(t)]=p+r
$$

where $r$ is the variance of the measurement error $v(t)$. The three parameters, $p, B$, and $r$, are computed by analyzing the statistical properties of the $z(t)$ time series. These three site-specific parameters are needed to define this component of the uncertainty relationship. The Kalman filter utilizes these three parameters to determine the average relative variance of the errors of estimation of discharges as a function of the number of discharge measurements per year (Moss and Gilroy, 1980). 
If the recorder at the primary site fails and there are no concurrent data at other sites that can be used to reconstruct the missing record at the primary site, there are at least two ways of estimating discharges at the primary site. A recession curve could be applied from the time of recorder stoppage until the gage was once again functioning or the expected value of discharge for the period of missing data could be used as an estimate. The expected-value approach is used in this study to estimate $V_{e}$, the relative error variance during periods of no concurrent data at nearby stations. If the expected value is used to estimate discharge, the value that is used should be the expected value of discharge at the time of year of the missing record because of the seasonality of the streamflow processes. The variance of streamflow, which also is a seasonally varying parameter, is an estimate of the error variance that results from using the expected value as an estimate. Thus the coefficient of variation squared $\left(c_{v}\right)^{2}$ is an estimate of the required relative error variance $V_{e}$. Because $C_{v}$ varies seasonally and the times of failures cannot be anticipated, a seasonally averaged value of $C_{v}$ is used:

$$
\tau_{v}=\left[\frac{1}{365} \sum_{i=1}^{365}\left(\frac{\sigma_{i}}{\mu_{i}}\right)^{2}\right]^{1 / 2}
$$

where

$\sigma_{i}$ is the standard deviation of daily discharges for the $i^{\text {th }}$ day of the year,

$\mu_{i} \quad$ is the expected value of discharge on the $i^{\text {th }}$ day of the year, and $\left(\bar{C}_{v}\right)^{2}$ is used as an estimate of $v_{e}$.

The variance $V_{r}$ of the relative error during periods of reconstructed streamflow records is estimated on the basis of correlation between records 
at the primary site and records from other gaged nearby sites. The correlation coefficient $\rho_{C}$ between the streamflows with seasonal trends removed at the site of interest and detrended streamflows at the other sites is a measure of the goodness of their linear relationship. The fraction of the variance of streamflow at the primary site that is explained by data from the other sites is equal to $\rho c^{2}$. Thus, the relative error variance of flow estimates at the primary site obtained from secondary information will be

$$
v_{r}=\left(1-\rho_{c}^{2}\right) \bar{c}_{v}^{2}
$$

Because errors in streamflow estimates arise from three different sources with widely varying precisions, the resultant distribution of those errors may differ significantly from a normal or log-normal distribution. This lack of normality causes difficulty in interpretation of the resulting average estimation variance. When primary and secondary data are unavailable, the relative error variance $V_{e}$ may be very large. This could yield correspondingly large values of $\bar{V}$ in equation (3) even if the probability that primary and secondary information are not available, $\varepsilon_{e}$, is quite small.

A new parameter, the equivalent Gaussian spread (EGS), is introduced here to assist in interpreting the results of the analyses. If it is assumed that the various errors arising from the three situations represented in equation (3) are log-normally distributed, the value of EGS was determined by the probability statement that

$$
\text { Probability }\left[e^{-E G S} \leq\left(q_{C}(t) / q_{T}(t)\right) \leq e^{+E G S}\right]=0.683
$$

Thus, if the residuals in $q_{c}(t)$ - in $q_{T}(t)$ were normally distributed, (EGS) ${ }^{2}$ would be their variance. Here EGS is reported in units of percent because EGS is defined so that nearly two-thirds of the errors in instantaneous streamflow data will be within plus or minus EGS percent of the reported values. 
It is assumed that, if the sensing or recording equipment at a stream gage fails between service visits to the gage, the time, $\tau$, from the last service visit until the failure has a conditional probability distribution that is defined by the truncated negative exponential family

$$
\mathrm{f}_{\tau}=k \mathrm{e}^{-k \tau} /\left(1-\mathrm{e}^{-k s}\right)
$$

where $s$ is the interval between visits and $k$ is a parameter of the family of probability distributions $(1 / \mathrm{k}$ is the average time to failure). It also is assumed that the recorder continues to malfunction from the instant of failure until the next service visit. Thus, the fraction of $t i m e, \varepsilon_{f}$, that the gage can be expected to function properly is

$$
\varepsilon_{\mathrm{f}}=1-E[\mathrm{~d}] / \mathrm{s}
$$

where $E[\cdot]$ is the expected value of the random variable contained in the brackets and $d$ is the downtime of the recorder between visits. Downtime is defined

$$
d= \begin{cases}s^{-\tau} & \text { if a failure occurs } \\ 0 & \text { if no failure occurs }\end{cases}
$$

as is shown in figure 16 .

The expected value of downtime is

$$
E[d]=\int_{0}^{s}(s-\tau) E_{\tau} d_{\tau}
$$

which when evaluated results in

$$
E[d]=\left(k s+e^{-k s}-1\right) / k
$$

Substituting equation 20 into equation 17 and simplifying result in

$$
\varepsilon_{f}=\left(1-e^{-k s}\right) / k s
$$

The fraction of time, $\varepsilon$, that no record is available at the station oi interest and no record is available from an auxiliary site to reconstruct at the station of interest (both caused by equipment failures) is obtainable from a bivariate application of equation 16 . If it is assumed that the probability distributions of failure times are identical and independent at the primary and auxiliary sites and that the primary and auxiliary sites are serviced at about the same times, $\varepsilon_{\mathrm{e}}$ can be evaluated as follows. 


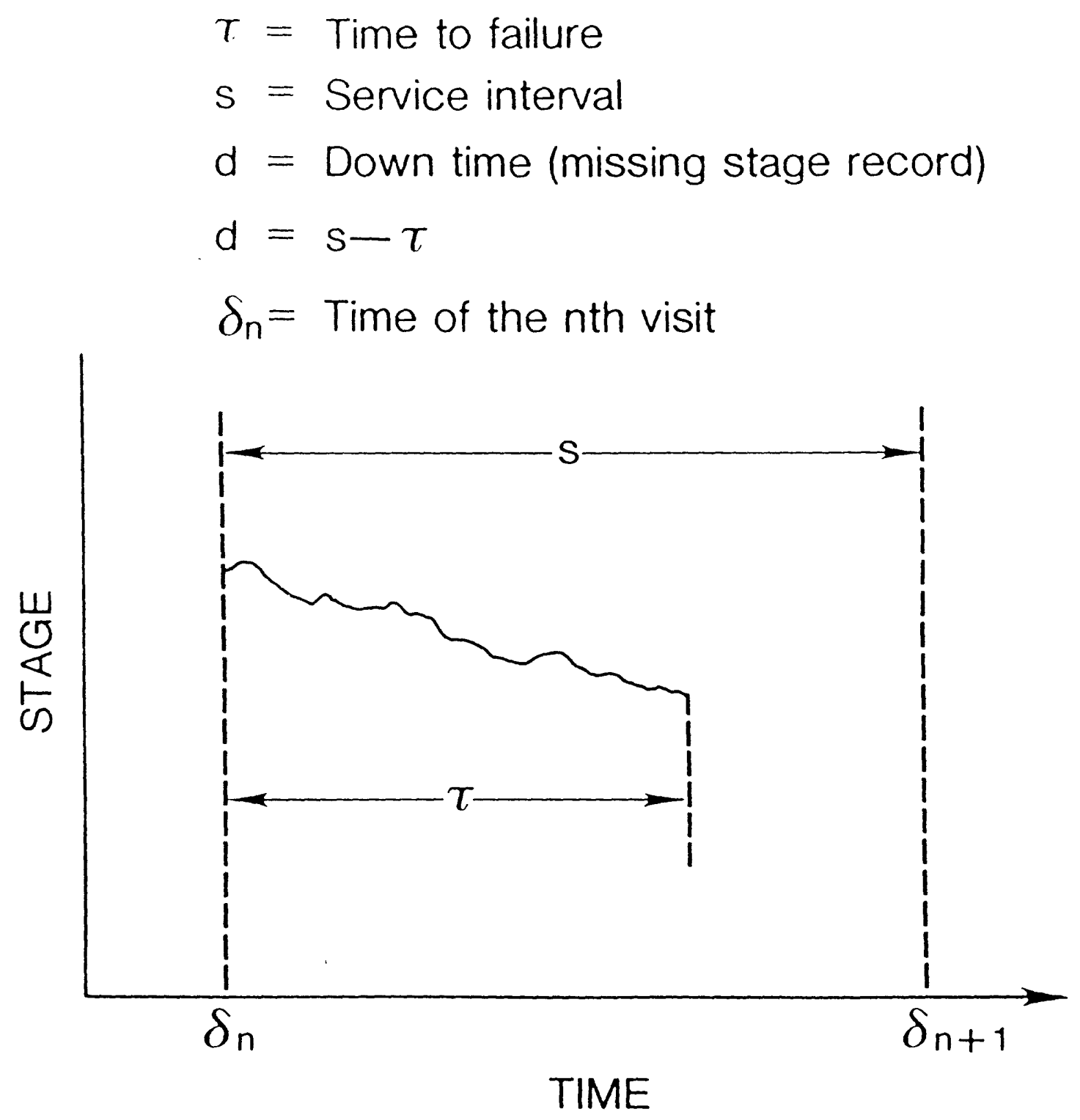

Figure 10.--Nomogram showing definition of downtime for a single station. 
The concurrent downtime, $d_{2}$, of both stations is defined

$$
d_{2}=\left\{\begin{array}{l}
\min \left(s-\tau_{a}, s-\tau\right) \text { if both stations fail, } \\
0 \text { otherwise }
\end{array}\right.
$$

where $\tau_{a}$ is the time to failure at the auxiliary site. The case in which $s-\tau_{a}$ is the minimum and equals $d_{2}$ is shown in figure 17. The value of $\varepsilon_{e}$ can be defined in terms of $\mathrm{d}_{2}$ as

$$
\varepsilon_{\mathrm{e}}=E\left[d_{2}\right] / \mathrm{s}
$$

The expected value of concurrent downtime is

$$
E\left[d_{2}\right]=\int_{0}^{s}(s-\tau) P\left[\tau_{C} \leq \tau\right] f_{\tau} d \tau+\int_{0}^{s}\left(s-\tau_{C}\right) P\left[\tau \leq \tau_{C}\right] f_{\tau_{C}} d_{\tau}
$$

where $P[\cdot]$ is the probability of the event contained within the brackets occurring. Evaluation of equation 24 under the given assumptions results in

$$
E\left[d_{2}\right]=s-\frac{2}{k}\left(1-e^{-k s}\right)-\frac{1}{2 k}\left(1-e^{-2 k s}\right)
$$

which can be substituted into equation 23 to obtain $\varepsilon_{\mathrm{e}}$.

Because $\varepsilon_{f}, \varepsilon_{e}$, and $\varepsilon_{r}$ are mutually exclusive and all encompassing

$$
\varepsilon_{f}+\varepsilon_{e}+\varepsilon_{r}=1 \text {. }
$$

From equation $26, \varepsilon_{r}$ can be defined

$$
\varepsilon_{r}=1-\varepsilon_{f}-\varepsilon_{e}
$$




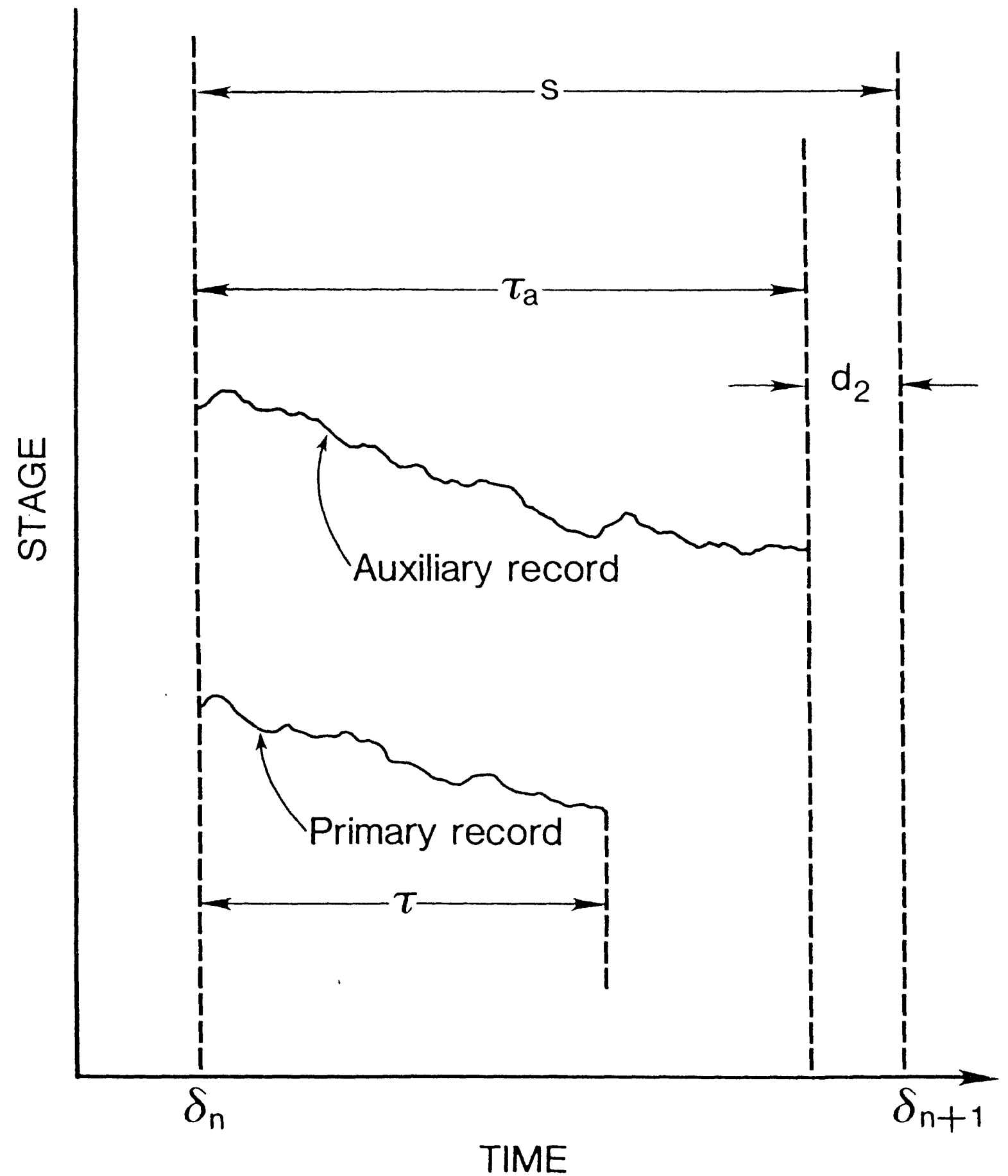

Figure 11.--Diagram showing definition of joint downtime for a pair of stations. 